\title{
Characterization of the caspase family in zebrafish
}

\author{
Olivia Spead, Tine Verreet, Cory J. Donelson, Fabienne E. Poulain* \\ Department of Biological Sciences, University of South Carolina, Columbia, South Carolina, United States of \\ America \\ * fpoulain@mailbox.sc.edu
}

\section{Abstract}

First discovered for their role in mediating programmed cell death and inflammatory responses, caspases have now emerged as crucial regulators of other cellular and physiological processes including cell proliferation, differentiation, migration, and survival. In the developing nervous system, for instance, the non-apoptotic functions of caspases have been shown to play critical roles in the formation of neuronal circuits by regulating axon outgrowth, guidance and pruning. How caspase activity is spatially and temporally maintained at sub-lethal levels within cells remains however poorly understood, especially in vivo. Thanks to its transparency and accessibility, the zebrafish offers the unique ability to directly visualize caspase activation in vivo. Yet, detailed information about the caspase family in zebrafish is lacking. Here, we report the identification and characterization of 19 different caspase genes in zebrafish, and show that caspases have diverse expression profiles from cleavage to larval stages, suggesting highly specialized and/or redundant functions during embryonic development.

\section{Introduction}

Caspases are highly conserved intracellular cysteine-dependent proteases best known for their critical role in mediating apoptosis and inflammatory responses [1,2]. As transducers and executioners of programmed cell death, caspases are especially important during development, when the elimination of unnecessary cells contributes to tissue morphogenesis [3]. In the nervous system, for instance, apoptosis has been detected in neural precursor cells, postmitotic neurons and glial cells [4], and a lack of caspase- 3 or -9 has been shown to cause brain hyperplasia and neural overgrowth in mice [5-8]. More recently, caspases have also emerged as central mediators of non-apoptotic signaling pathways regulating a large variety of cellular and physiological functions [9-12]. How caspase activation is induced and maintained at sublethal levels within cells remains however poorly characterized.

Caspases are synthesized as zymogens that become activated upon oligomerization or cleavage at specific aspartate residues. They comprise an $\mathrm{N}$-terminal prodomain of varying size and a catalytic CASc domain that includes a large P20 and a small P10 subunits. So far, 12 caspases have been identified in human (Caspases- 1 to $10,-12$, and -14 , with -12 being inactive due to 
deleterious mutations), and additional caspases including Caspases-11 and -13 (murine and bovine orthologs of human Caspase-4, respectively), -15, -16, -17 and -18 have been detected in other vertebrates [13-17]. Based on their functional and structural similarities, caspases have generally been classified as inflammatory (Caspases- $1,-4,-5$ and -12 ) and initiators (Caspases-2, -8, -9 and -10) or executioners of apoptosis (Caspases-3, -6 and -7). However, this subdivision has progressively become obsolete with the discovery of functions in additional processes including cell proliferation [18], differentiation [19, 20], motility and migration [11, 21], survival [22] and tissue regeneration and repair [23].

Essential non-apoptotic functions of caspases have especially been demonstrated in the developing and mature nervous system [10, 12, 24, 25]. Caspase-3, for instance, has been implicated in the regulation of neural stem cell differentiation [26], Bergman glia differentiation [27, 28] synaptic plasticity, learning and memory [29-33]. More recently, caspases have also been identified as important regulators of axon outgrowth and pathfinding. The role of caspase activity in axon guidance was first suggested by the observation that growth cone responses to netrin or lysophosphatidic acid were blocked in the presence of caspase inhibitors in vitro [34]. Since then, caspases have been shown to regulate NCAM-dependent axon outgrowth [35], axon targeting in the auditory brainstem and the olfactory bulb [36, 37], and retinal axon arborization [38]. Caspases have also emerged as playing a crucial role in the refinement of neuronal connectivity by regulating axonal and dendritic pruning [39-44]. For instance, pruning of retinal axons projecting to the superior colliculus is delayed in mice lacking caspase- 3 or $-6[42,43]$.

How the non-apoptotic activity of caspases is spatially and temporally induced and restricted in cells or axons is not yet well understood. Several mechanisms have been proposed, including subcellular regulation by inhibitors such as XIAP [45] or post-translational modifications [12]. Yet, our understanding of when, where and how caspases are locally activated and controlled in vivo remains rudimentary due to a limited number of models suitable for high resolution in vivo imaging. Thanks to their advantageous accessibility and transparency, zebrafish embryos offer the unique ability to directly visualize axon development and degeneration in vivo and address these questions $[46,47]$. The recent use of genetically encoded biosensors to detect caspase activation in real time in this model has revealed an important function of Caspases-3 and -9 in axon remodeling [38], and will likely provide new insight into the fine spatio-temporal activation of caspases in other contexts. Yet, detailed information about caspases in zebrafish is surprisingly lacking. To gain insight into the functions of caspases during axon guidance and pruning in vivo, we first carried out a comprehensive analysis of the caspase family in zebrafish. We report here the identification and characterization of 19 different caspase genes including known orthologs of human caspases as well as new members of this family. We also show that zebrafish caspases have distinct expression patterns during development, suggesting both specific and conserved functions among vertebrates.

\section{Material and methods}

\section{Zebrafish husbandry}

This research was approved by the University of South Carolina Institutional Animal Care and Use Committee (IACUC) (protocol number: 2398-101289-111717). Wild type (WT) embryos (Tübingen and $\mathrm{AB}$ strains) were obtained from natural matings, raised at $28.5^{\circ} \mathrm{C}$ in $\mathrm{E} 3$ medium ( $5 \mathrm{mM} \mathrm{NaCl}, 0.17 \mathrm{mM} \mathrm{KCl}, 0.33 \mathrm{mM} \mathrm{CaCl}_{2}$, and $0.33 \mathrm{mM} \mathrm{MgSO}_{4}$ ) in the presence of $150 \mathrm{mM}$ of 1-phenyl-2-thiourea (PTU) (Sigma) to prevent pigment formation, and staged by age and morphology [48]. Embryos were anaesthetized in tricaine (Western Chemicals) before fixation or RNA extraction. 


\section{Identification and cloning of caspase coding sequences}

GenBank and the Ensembl Danio rerio (GRCz10) databases were used to identify genomic loci for all zebrafish caspase genes. Mus musculus, Homo sapiens, Bos taurus, and Gallus gallus caspase gene sequences were blasted against the databases and the zebrafish sequences identified were confirmed for the presence of a CASc domain (SMART accession number SM00115). Zebrafish mRNA was isolated from embryos at cleavage, blastula sphere, gastrula shield, gastrula bud, pharyngula prim-5 (24 hours-post-fertilization (hpf)), long-pec (48 hpf), protruding mouth (72 hpf) and larval day 4 (96 hpf) stages using Trizol and the RNeasy mini kit (Qiagen), and cDNA was prepared from RNA using the SuperScriptIII First-Strand Synthesis system (Invitrogen). Full length primers (Table 1) were used to amplify zebrafish caspase cDNAs. Amplicons were subcloned into PCRII-TOPO (Invitrogen) and sequenced to verify gene identity and confirm sequence orientation for the generation of sense and antisense RNA probes. Protein sequences were analyzed using the Eukaryotic Linear Motif (ELM) resource prediction tool and Motif Scan (MyHits, SIB, Switzerland) to identify and annotate functional domains [49].

\section{Sequence comparison and phylogeny}

Zebrafish caspase protein sequences were compared to the following protein sequences using the MatGAT (Matrix Global Alignment Tool) software [50] with a BLOSUM 62 scoring matrix (gap opening and gap extending penalties of 4): Homo sapiens Caspase-1 (NP_150634), Caspase-2 (NP_116764), Caspase-3 (NP_116786), Caspase-4 (NP_001216), Caspase-5 (NP_0011 29584), Caspase-6 (NP_001217), Caspase-7 (NP_001253986), Caspase-8 (NP_001073594), Caspase-9 (NP_001220), Caspase-10 (NP_116759), Caspase-12 (NP_001177945), and Caspase-14 (NP_036246), Bos Taurus Caspase-15 (NP_001029681), Mus musculus Caspase-16 (XP_003945628), Gallus gallus Caspase-17 (UniProt A9YDV3), and Caspase-18 (NP_00103 8154). Phylogenetic analyses were conducted using the Mega 7 software [51] and included the

Table 1. Primers used for caspase cloning.

\begin{tabular}{|c|c|c|}
\hline Gene name & forward primer & reverse primer \\
\hline casp1 & ATGGCCAAATCTATCAAGG & TCAGAGTCCGGGGAA \\
\hline casp19a & ATGGAGGATATTACCCAG & TCACAGTCCAGGAAAC \\
\hline casp19b & ATGGAGGATATTACCAAGTTG & TCACTGTCCAGGGAAC \\
\hline casp23 & AATCGTCGTTTAGCGCTTTAG & GCAGATATATATTGCACTTGCTATG \\
\hline casp2 2 & ATGTTGGGAGAGTGC & TTAGTTGCTGGGGTAG \\
\hline casp9 & ATGGAGCAGAAACACAG & TCATGACTGTGAAGACTG \\
\hline casp $8 a$ & ATGGATCCTCAGATCTTTCACG & TCAGTCTATGGGCAGCACT \\
\hline casp $8 b$ & ATGGATAAAACTAGTAATCCTA & TTAGGAGACTCCATTCAT \\
\hline casp10 & GACATGGACATGTGTTTTCAGAG & GAGCATCATCAAGGAAGCC \\
\hline casp20 & ATGAGTAAAAAGGAATCAACTC & TCAGTTATTCACTGGCG \\
\hline casp22 & ATGGCAGATCAACTTTTGG & CTGTTTAAGAGAACCGGC \\
\hline casp3a & ATGAACGGAGACTGTGTG & TTAAGGAGTGAAGTACATCTCTTTG \\
\hline casp3b & ATGTCGCACGTGAAACCA & TTATTTAGGGAAGTAGAGTTCTTTGG \\
\hline casp6a & ATGGCAAGTCACACT & TTACTTTTTGGGCCTG \\
\hline casp6b & ATGGCAACTAACACCAGAAGC & CTATTGGATCTGAGTATTGTCTCTG \\
\hline casp6c & ATGCACCACAACAAATCAATAATG & GTAGGGATTAGGTATGGATTAG \\
\hline $\operatorname{casp} 7$ & ATGAATAAAGAAGCCCTTACTTCC & TCAGTTGAAGTAGAGCTCTTTAG \\
\hline $\operatorname{casp} 21$ & ATGAGTTTACAAGCTTCTAAAGAC & TTACAATTTCTTATTCTTCTCTGCAAC \\
\hline casp 17 & CAACACAAGCACTAATGTCAG & TCCTCATTTCTGTGATCTTCAG \\
\hline
\end{tabular}

https://doi.org/10.1371/journal.pone.0197966.t001 
following additional sequences: Gallus gallus Caspase-1 (XP_003642432.2), Caspase-2 (NP_001161173), Caspase-3 (NP_990056.1), Caspase-6 (NP_990057), Caspase-7 (Uniprot F1NV61), Caspase-8 (NP_989923.1), Caspase-9 (Uniprot F1NL59), Caspase-10 (XP_421 936.4), Latimeria chalumnae Caspase-1 (Uniprot H3B2V3), Caspase-2 (Uniprot H3A019), Caspase-3 (Uniprot H3ACL5), Caspase-6 (Uniprot H2ZXX5), Caspase-7 (Uniprot M3XIX0), Caspase-8 (Uniprot H3A526), Caspase-9 (Uniprot H3BFW5), Caspase-10 (Uniprot H2ZXE8), Caspase-14l (XP_014344655.1), Caspase-17 (Uniprot H3AXG0), Caspase-18 (H3A2R2), Oryzias latipes Caspase-1 (Uniprot H2LPF5), Caspase-2 (XP_011483724.1), Caspase-3a (NP_0010 98168.1), Caspase-3b (NP_001098140.1), Caspase-6 (Uniprot H2MXM9), Caspase-611 (XP_02 3813211.1), Caspase-612 (XP_023813213.1), Caspase-7 (XP_023805391.1), Caspase-8 (NP_001 098258.1), Caspase-9 (Uniprot H2LBD7), Caspase-17 (Augustus g31162.t1), Caspase-20 (XP_023820994.1), Takifugu rubripes Caspase-1 (Uniprot H2SKU3), Caspase-1l (Uniprot H2UDK1), Caspase-2 (H2UKY4), Caspase-3 (NP_001027871t), Caspase-6 (Augustus g16014. t2), Caspase-7 (Uniprot H2U497 and H2U498), Caspase-8 (Uniprot H2TIG5), Caspase-9 (Uniprot H2V836), Caspase-10 (Uniprot H2V630 and H2V635), Caspase-17 (Uniprot H2VE U2), Caspase-20 (Uniprot H2THL4), Gasterosteus aculeatus Caspase-1 (Uniprot G3P6H8), Caspase-11 (Augustus g16792.t3), Caspase-2 (Uniprot G3P808), Caspase-3a (Augustus g8732. t3), Caspase-3b (Uniprot G3Q4K5), Caspase-3c (Uniprot G3Q4L2 and BT027477), Caspase-6 (Uniprot G3PZL5), Caspase-7 (Augustus g18074.t1), Caspase-8 (NP_001254591), Caspase-9 (Augustus g27457.t1), Caspase-10 (NP_001254593), Caspase-17 (Augustus g16285.t1) and Caspase-20 (Augustus g4015.t1). Multiple alignment of 90 caspase protein sequences was generated with Muscle [52] and visualized with Jalview software [53]. The evolutionary history was inferred by using the Maximum Likelihood method based on the Whelan And Goldman + Freq. model [54]. Initial trees for the heuristic search were obtained by applying the Neighbor-Joining method to a matrix of pairwise distances estimated using a JTT model. A discrete Gamma distribution was used to model evolutionary rate differences among sites ( 5 categories $(+\mathrm{G}$, parameter $=1.4388)) .500$ bootstrap replications were used as a test of phylogeny, with values indicated next to the branch. The tree is drawn to scale, with branch lengths measured in the number of substitutions per site.

\section{RT-PCR}

CDNA was prepared from different developmental stages as mentioned above and used for RT-PCR. Full length primers (Table 1) were used to amplify casp 1, casp $3 a$, casp $3 b$, casp $6 a$, casp6b, casp7, casp 17, casp 19a, casp 19b, casp21 and casp22. Different primers were used for the following caspases: casp2_fw: TAATGTGAGGTTCGACTCAG; casp6c_rv: TCCAGTTGTGAACG ATAACG; casp8a_fw: CTACGATGTGATAATTCTCGT; casp8b_fw: ACAGATGAACCGAAGAGG; casp9_fw: AATACAGAGCAAGGCAACC; casp10_fw: CACGAGACCTCAACACTG; casp10_rv: GTGAATGTCTGAGGAAACAC; casp20_fw: TGACTACAATAACCTCTCTGATG; and casp23_fw: TCCAATTCTGAAGTGCAACT. The following primers were used to amplify actin as a control: actin_fw: ATCCCAAAGCCAACAGAGAG; actin_rv: CAACGGAAACGCTCATTGC.PCR reactions were conducted using 30 to 36 cycles.

\section{In situ hybridization}

In vitro transcription of digoxigenin-labeled probes was performed using the RNA Labeling Kit (Roche Diagnostics Corporation) according to manufacturer's instructions. Embryos were dechorionated at the appropriate developmental stages and fixed in $4 \%$ paraformaldehyde in phosphate buffered saline ( $\mathrm{pH} 7.4)$ for 2 hours at room temperature and overnight at $4^{\circ} \mathrm{C}$. Whole-mount in situ hybridization was performed as previously described [55]. Sense probes 
were used as controls for all caspases and did not reveal any staining. After staining, embryos were cleared in $80 \%$ glycerol for imaging. Images were acquired using an Olympus SZX16 stereomicroscope equipped with an Olympus DP80 dual color camera and Cellsens standard software. Digital images were cropped and aligned using Adobe Photoshop.

\section{Results and discussion}

\section{Identification of zebrafish caspases}

13 caspase genes (casp) have been identified in human, including casp 1 to 10,12, 14 and $16 p$ (casp16p being a pseudogene) $[16,17]$. Additional caspases have been detected in other vertebrates and include mammalian casp15 (absent in the human and mouse genomes) [15], casp17 (present in all vertebrate lineages except for therian mammals), and casp18 (present in chicken but absent in placental mammals) [16]. We blasted these sequences against GenBank and Ensembl Danio rerio (GRCz10) EST databases to identify corresponding zebrafish caspases and found 19 casp genes (Table 2). Some of these genes were reported previously but were not always named according to the accepted caspase nomenclature [16, 56-59]. Other genes we identified have never been described before. We named all caspase genes according to their similarity to the vertebrate orthologs, and attributed new numbers based on the taxonomy proposed in previous studies [16]. The accession numbers of all genes from the different databases are shown in Table 2, and new GenBank accession numbers were obtained for all sequences.

Table 2. Nomenclature and accession numbers of zebrafish caspases.

\begin{tabular}{|c|c|c|c|c|c|}
\hline $\begin{array}{l}\text { Gene } \\
\text { name }\end{array}$ & other / previous names & $\begin{array}{c}\text { GRCz10 chromosome location } \\
\text { (strand) }\end{array}$ & Ensembl Gene ID & Genbank Acc \# (old) & $\begin{array}{c}\text { Genbank Acc \# } \\
\text { (new) }\end{array}$ \\
\hline casp1 & caspase-a, caspy, zgc:109869 & chr16:42,043,825-42,054,428 (-) & ENSDARG00000008165 & BC095022 & MG957992 \\
\hline casp19a* & $\begin{array}{l}\text { caspase-b, caspy2, zgc:109807 } \\
\text { caspase-1A, si:ch211-233g6.8 }\end{array}$ & chr1:57,315,773-57,323,452(-) & $\begin{array}{l}\text { ENSDARG00000052039 } \\
\text { ENSDARG00000075270 }\end{array}$ & $\begin{array}{l}\text { BC095000, } \\
\text { DQ022755 }\end{array}$ & MG958005 \\
\hline casp19b* & caspase-bl, caspase-b1, si:ch211-15j1.6 & chr1:57,370,656-57,376,144(-) & ENSDARG00000094433 & - & MG958006 \\
\hline casp $23^{*}$ & caspase-c, zgc:113326, zgc:171731 & chr7:19,348,435-19,352,383(+) & ENSDARG00000014657 & BC151948 & MG958010 \\
\hline casp2 & caspase-2 & chr16:17,643,307-17,669,604 (-) & ENSDARG00000062052 & BC163115 & MG957993 \\
\hline casp9 & im:7136887, zgc:101776 & chr23:25,047,448-25,058,524 (+) & ENSDARG00000004325 & BC097103 & MG958002 \\
\hline casp $8 a$ & $z g c: 92075$ & chr6:12,811,868-12,821,422(+) & ENSDARG00000058325 & BC081583 & MG958000 \\
\hline casp $8 b$ & caspase-8l1 & chr6:12,862,945-12,867,126(+) & ENSDARG00000058341 & DQ812121 & MG958001 \\
\hline casp10 & caspase- $8 l 2$, caspase $-8 b$ & chr9:1,343,221-1,355,521(+) & ENSDARG00000070272 & DQ812123 (partial) & MG958003 \\
\hline casp $20^{*}$ & $\begin{array}{c}\text { caspxa,caspxb, zgc: } 194469 \\
\text { CARD-Casp } 8\end{array}$ & chr6:12,878,158-12,881,286 (-) & ENSDARG00000058347 & BC163666 & MG958007 \\
\hline casp $22^{*}$ & si:dkey-103e21.5 & chr5:22,081,469-22,086,320 (-) & ENSDARG00000091926 & BC133883 & MG958009 \\
\hline casp $3 a$ & caspase- $3 a, z g c: 100890$ & chr1:16,835,237-16,841,582(+) & ENSDARG00000017905 & BC078310 & MG957994 \\
\hline casp $3 b$ & caspase $-3 b$ & chr14:4,022,953-4,036,126 (-) & ENSDARG00000055045 & DQ812120 & MG957995 \\
\hline casp $6 a$ & caspase-6a, zgc:112960 & chr3:32,830,371-32,834,050 (-) & ENSDARG00000093405 & BC094299 & MG957996 \\
\hline casp $6 b$ & caspase- $6 b, z g c: 103604$ & chr3:32,822,780-32,826,756 (-) & ENSDARG00000025608 & BC083437 & MG957997 \\
\hline casp6c & caspase- $6 c$, zgc: 136946 & chr3:32,837,963-32,841,789 (-) & ENSDARG00000070368 & BC114318 & MG957998 \\
\hline casp7 & $z g c: 110595$ & chr12:30,456,171-30,467,659 (-) & ENSDARG00000091836 & BC095327 & MG957999 \\
\hline casp $21^{*}$ & CABZ01041682.1; FO834888.1 & $\operatorname{chr} 21: 8,440,994-8,445,761(+)$ & ENSDARG00000055550 & - & MG958008 \\
\hline casp17 & CU467905.1 & chr10:42,334,831-42,350,374(+) & $\begin{array}{c}\text { ENSDARG00000086266 } \\
\text { (partial) }\end{array}$ & - & MG958004 \\
\hline
\end{tabular}

* new number attributed

https://doi.org/10.1371/journal.pone.0197966.t002 
For simplicity, we analyzed zebrafish caspases based on the initial classification of caspases into inflammatory, initiator and executioner groups (Fig 1). In human, genes encoding inflammatory caspases include casp1, casp4, casp5, and casp12 and are clustered on chromosome 11,

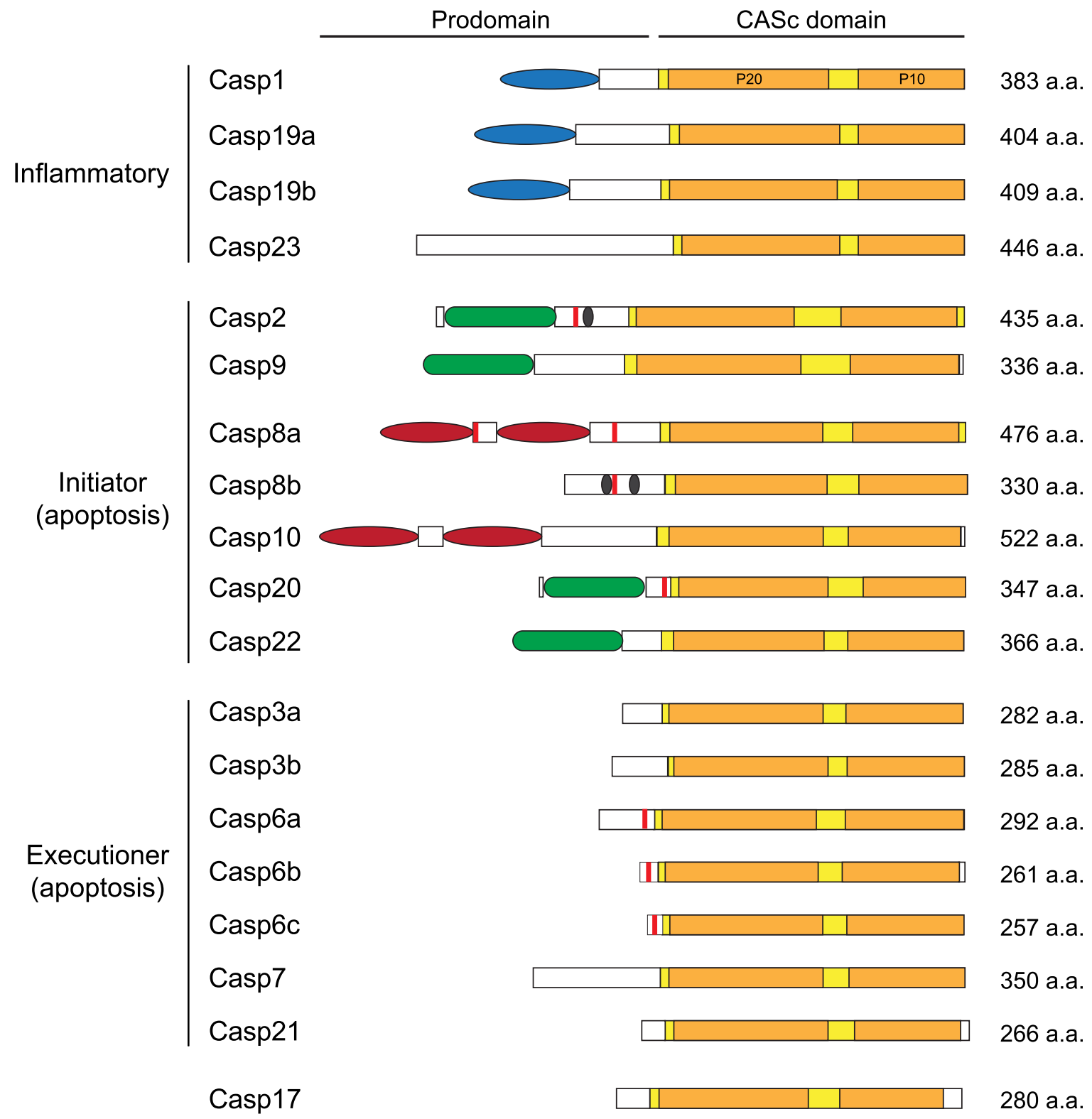

\begin{tabular}{|l|l|}
\hline$\square$ CASc domain with large and small subunits & I Traf2 binding site \\
Pyrin domain & O Nuclear localization signal \\
CARD domain & \\
DED domain & \\
\hline
\end{tabular}

Fig 1. Domain structure of zebrafish caspases. Caspases are presented based on the classical classification of caspases as inflammatory, initiator, or executioner. The catalytic CASc domain is indicated in yellow, with large and small subunits in orange. CARD: caspaserecruitment domain; DED: death-effector domains. 
suggesting they may have originated from gene duplication events. In contrast, we found zebrafish casp1, casp19a, casp19b and casp23 genes on three different chromosomes (Table 2) and did not observe any conserved chromosomal synteny with human caspases (data not shown). Surprisingly, we could only find one or two inflammatory caspase genes in other teleost species (casp1 in medaka and casp1/1l in stickleback and fugu) and did not identify any casp23 ortholog. Phylogenetic analysis of caspase sequences across vertebrates revealed that zebrafish inflammatory caspases cluster in a separate group, suggesting the occurrence of duplication events specific to that lineage (Fig 2). Interestingly, comparison of caspase protein sequences

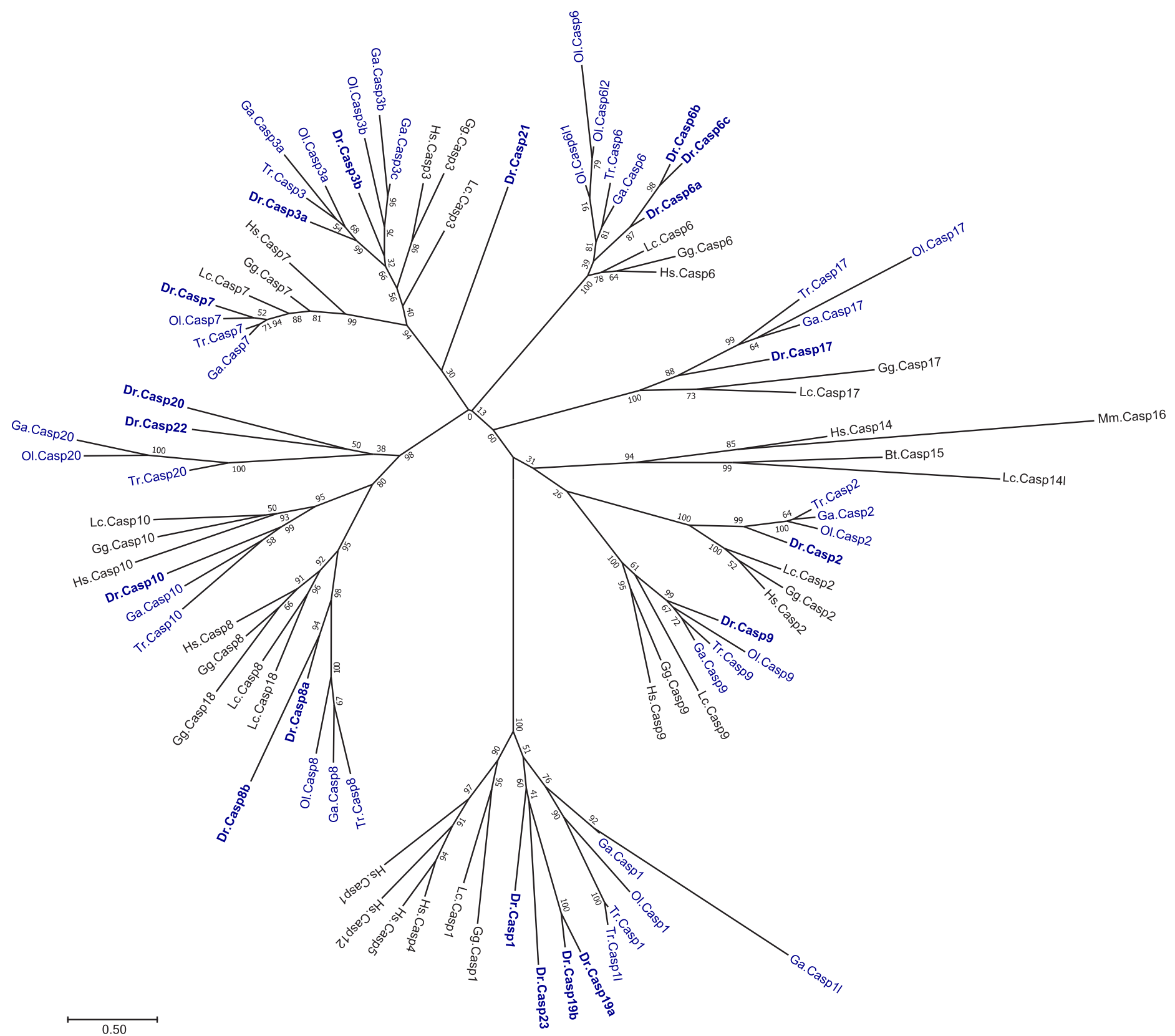

Fig 2. Phylogenetic tree of zebrafish and other relevant vertebrate caspases. A phylogenetic comparison was conducted for caspase protein sequences from zebrafish (Dr), human (Hs), mouse (Ms, used for Casp16), cow (Bt, used for Casp15), chicken (Gg), coelacanth (Lc), medaka (Ol), stickleback (Ga) and fugu (Tr). Teleost species are indicated in blue, with zebrafish in bold. 500 bootstrap replications were used as a test of phylogeny, with values indicated next to the branch.

https://doi.org/10.1371/journal.pone.0197966.g002 
shows that zebrafish Caspase-1 (previously known as Caspy [56]) is the most similar to human Caspase- 1 , sharing $38 \%$ identity and $56 \%$ homology (Table 3 ). Analysis of the conserved catalytic CASc domain also indicates that zebrafish Caspase- 1 has a His at position 318 that is not conserved in Caspases-19a, -19b and -23 (Fig 3). His 318 is similar to His 342 in human Caspase- 1 that binds the specific $\mathrm{P} 3$ alanine residue of Caspase-1 substrates [60], suggesting functional conservation. Caspases-19a and $19 \mathrm{~b}$ are $70 \%$ identical (Table 4 ) and phylogenetically cluster together, indicating they are recent duplicated isoforms. While mammalian inflammatory caspases are characterized by the presence of a caspase-recruitment domain (CARD) in their N-terminal region [61], Caspases-1, -19a and -19b share a pyrin (PYR) domain in its place. Interestingly, these PYR domains appear specific to zebrafish caspases, as Caspases-1 and -11 in other teleosts possess a CARD domain similar to mammals. Although in the same group, Caspase-23 differs from the other inflammatory caspases by the absence of a PYR or CARD domain in its $\mathrm{N}$-terminal region (Fig 1). Caspase-23 also possesses an unusual QSCRG cysteine active site (positions 340-344) in its CASc domain instead of the conserved QACRG pentapeptide found in other caspases (Fig 3). Interestingly, a similar QSCRG is found in amphoxius and sea snail caspases $[62,63]$, suggesting an ancient origin.

Genes encoding initiator caspases in mammals include casp2, casp9, and the subfamily of casp 8 and casp 10 . Another caspase belonging to the caspase- 8 subfamily, casp 18 , has been detected in chicken and opossum but is not present in eutherian mammals [16]. As previously reported $[17,58,59,64]$, we identified orthologs for casp2, casp9, casp8 (as casp8a and casp8b), and casp 10 but not for casp 18 in zebrafish (Tables 2 and 3, Fig 2). We also detected additional caspase genes belonging to the caspase- 8 subfamily that we named casp 20 and casp22. Like in mammals, zebrafish Caspase- 2 and Caspase- 9 are characterized by the presence of a CARD in their N-terminal region (Fig 1). Caspase-8a and Caspase-10, on the other hand, possess two death-effector domains (DEDs). Interestingly, the $\mathrm{N}$-terminal pro-domain of Caspase-8b is much shorter and lacks these DED motifs. It notably includes two nuclear localization signals not detected in Caspase-8a (Fig 1). Despite these differences, the CASc domains of Caspase-8a and Caspase- $8 \mathrm{~b}$ are very similar (62\% identity and 77\% homology) and possess the QACQG active site characteristic of human Caspase-8 (Fig 3), indicating that both caspases are duplicated isoforms. The adjacent localization of casp $8 a$ and casp $8 b$ genes on chromosome 6 further suggests a common origin from a recent gene duplication event. This duplication appears specific to the zebrafish lineage, as no $c a s p 8 b$ could be identified in other teleosts including fugu, medaka and stickleback (S1 Fig). In addition to casp $8 a$ and casp $8 b$, we detected another para$\log$ on chromosome 6 that we named casp20. This paralog has been described in previous studies as CARD-Casp8 due to the presence of a CARD in the $\mathrm{N}$-terminal pro-domain instead of the two DED domains present in Caspases-8, -10 and -18 [58, 59] (Fig 1). Interestingly, comparative genomics and phylogenetic analyses suggest that casp 8 , casp 10, casp 18 originate from a common ancestor during vertebrate evolution (Fig 2) [59]. Casp8, casp18 and casp10 genes are clustered on the same chromosome in chicken, coelacanth and spotted gar genomes (S1 Fig and [59]). While casp18 has been lost in the human genome (and in other eutherian mammals), casp 8 and casp 10 remain clustered on chromosome 2 (S1 Fig). In contrast, casp 8 and casp10 have been segregated on different chromosomes in the teleost lineage after extensive chromosomal rearrangements during evolution (S1 Fig). Similarly to casp18 in other species, casp 20 is found in close proximity to casp 8 in all teleost genomes (casp $8 b$ in zebrafish) but could not be identified in other vertebrates including shark, lamprey and gar. The clustering of casp 8 , casp 18 and casp 10 in the genome of spotted gar, whose lineage represents the unduplicated sister taxon of teleosts [65], suggests that casp 8 , casp18 and casp10 genes formed an ancestral cluster in vertebrates that has been dispersed during teleost evolution. Casp20 might have derived from casp18 by domain shuffling from DED to CARD or might have arisen as a 


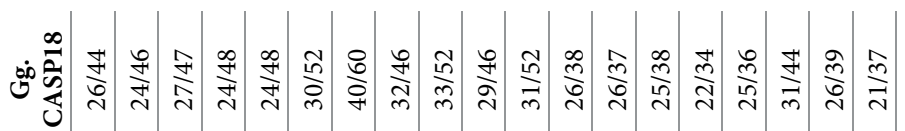

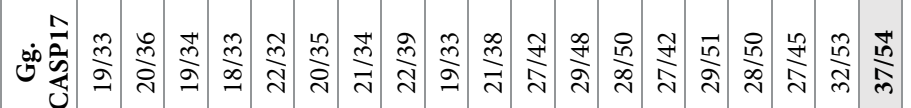

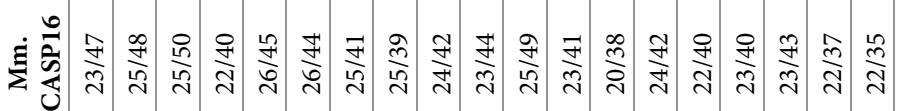

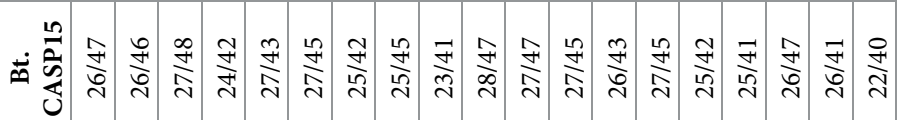

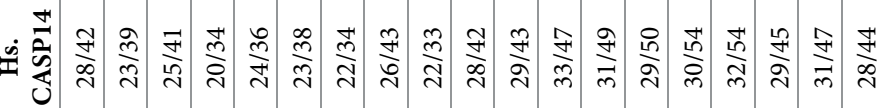

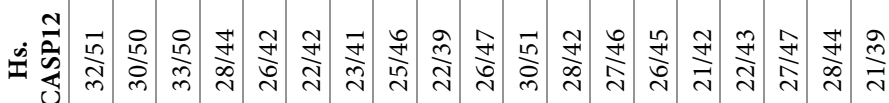

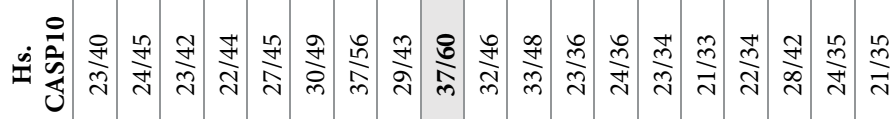

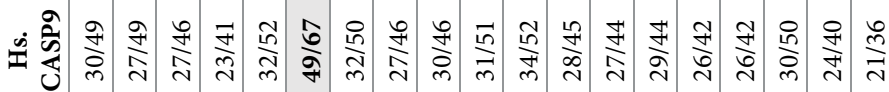

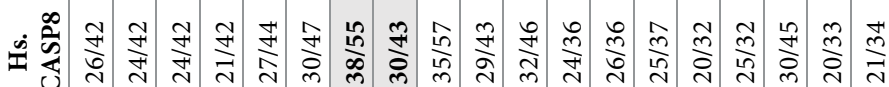

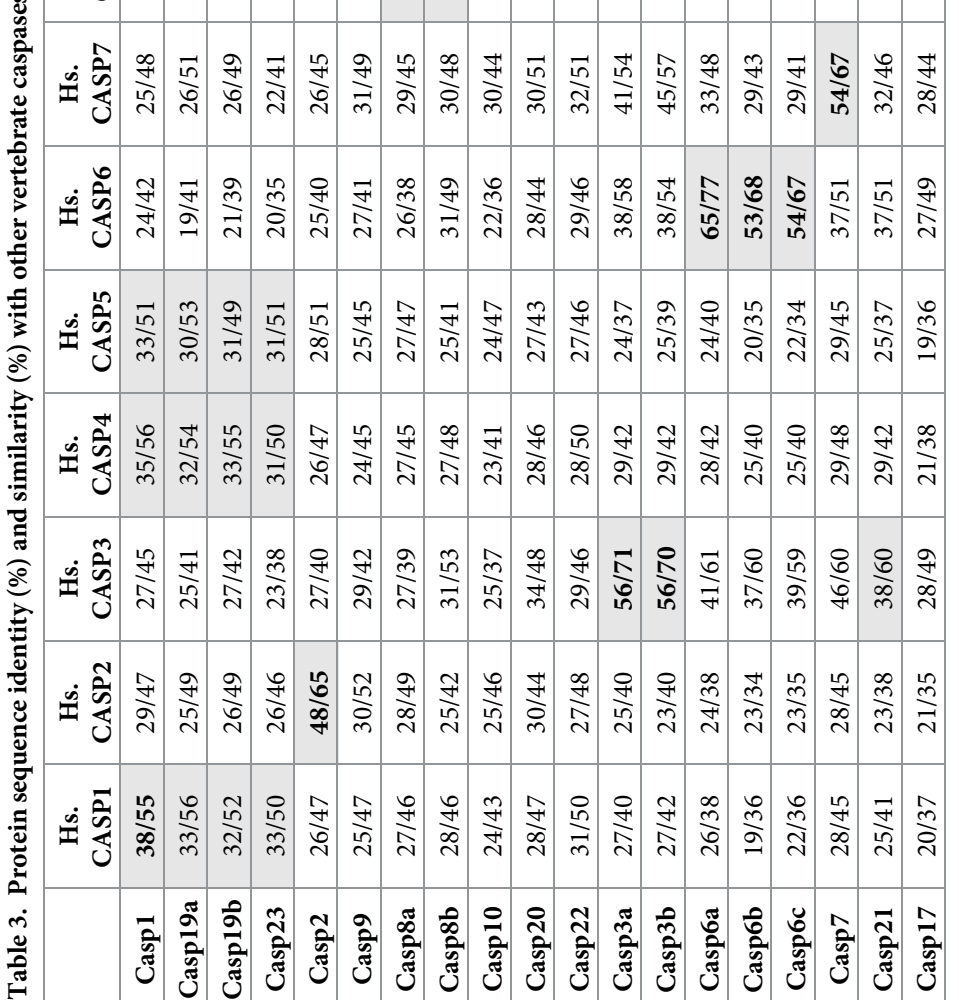

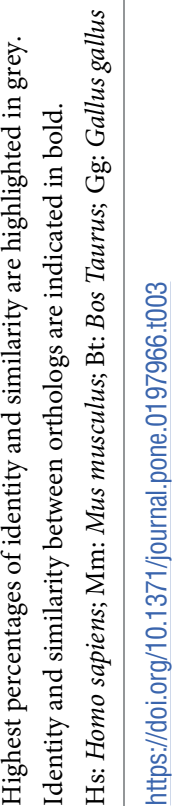




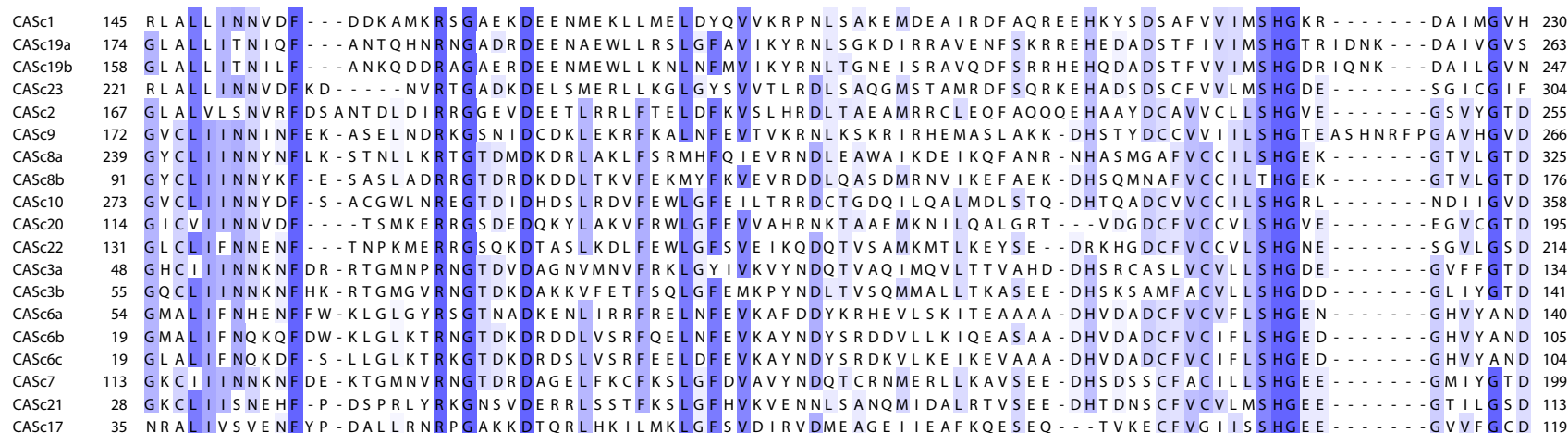

\begin{tabular}{|c|c|c|}
\hline & & \\
\hline Sc19a & 264 & I DKPKVILIQACRGGQSSGVLAQDSVFA. \\
\hline CASc19b & 248 & NWL QNRNDVYFVEDTFSHLNSVNCPALI DKPKVILIQACRGGQL-GGVPVKDCVP. \\
\hline CASc23 & 305 & 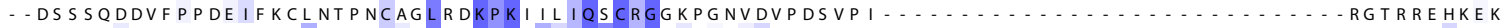 \\
\hline $15 c 2$ & 256 & $\ldots . .$. GQLLELDWVFEVFDNARCPLLQNKPKMFF IQACRGEEMDNGVDQLDGQERTQSPGCEQRDAGREGERDNREKKEEKERERLRVKLPQRS \\
\hline CASc9 & 267 & $\ldots . .-$ GPAVPIQIITNYLNGQNCPSLQGKPKLFFIQACGGGEKDIGFEVSPDDVQPSIGGIDDEMDAIPMSSSSDSLSTASDELDARASLPTPS \\
\hline CASc8a & 326 & $\cdots-1$ GKPVEIREVTLPFAG - CRTLASKRKLFFIQACQGDENQAGVWTSDGRE $\cdots \cdots$ \\
\hline CASc8b & 177 & $\cdots-1$ GKQVPIRELSQPFAE - C CRSLASKRKLFFIQACQGNMRQQGLWMAHERE \\
\hline Sc10 & 359 & $\ldots \ldots$ GKAVPFKELMETLSPFRCSSLYQKPKLFF IQACRGTQNQRAVFPQTFTE $\ldots \ldots \ldots \ldots$ \\
\hline CASc20 & 196 & $\cdots \ldots$ GSLVSVDEIRDPFTGVNCQKLVGKPKLFFIQACRGQRKQLRVNAQADGP $\ldots \ldots \ldots \ldots \ldots$ \\
\hline CASc22 & 215 & $\ldots \ldots$ EQICPVDDITSPFNGANCSALAGKPKVFFIQACRGHEIQSKVMVADDSG $\ldots \ldots \ldots \ldots \ldots$ \\
\hline Sc3a & 135 & $\cdots-1$ TS - VDLKSLTSLFRGDRCPSLVGKPKLFFIQACRGTELDPGVETDHPDH $\ldots \ldots$ \\
\hline scc3b & 142 & $\cdots \ldots$ DS - IELKRLFAHFRGDRCTSLVGKPKLFFIQACRGTDLDSGIECDGVGD $\ldots \ldots \ldots \ldots \ldots \ldots$ \\
\hline CASc6a & 141 & 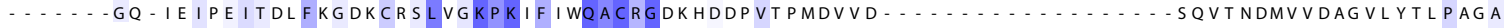 \\
\hline CASc6b & 106 & 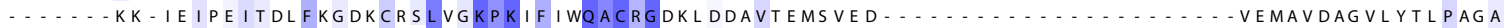 \\
\hline Sc6c & 105 & 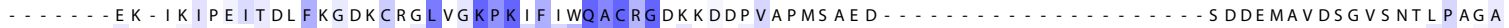 \\
\hline CASC7 & 200 & $\cdots \ldots$ GA - MPIKTMTSLFKGDVCKSLVGKPKLFFIQACRGSEFDDGVQTDSGPP $\ldots \ldots \ldots$ \\
\hline Sc21 & 114 & $\ldots \ldots$ ERWIPVKTLTSLLTSDLCPSLRDKPKIFFLQACRGVEYDPGVEADSVEA $\ldots \ldots \ldots \ldots$ \\
\hline ISc17 & 120 & 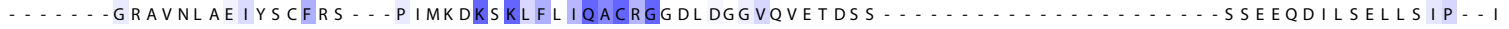 \\
\hline Sc & 302 & DVF IKCA - HEDHIEELFRKVLRRFD ........ NPNMIGNFKQMACK .... \\
\hline CASc19a & 322 & DFVCFMSTMPNT - FAYRNPIEGSFFISYIVDVFCSSA-HRDDIMELFRKVTLRME - . - KDQRFQGQAKLLPCI . - ERTSISKRFYL \\
\hline CASc & 3 & DFVCFMSTMPDV - VAYRDEVKGSYFISYIVDVFCSSA-CKDHIMELFRKVAARME - - - KDERFRRQAKLLPCI - - E \\
\hline CASc23 & 369 & DFCCFRSSTPDT - VSYYRNKEKGSHFIQDLVEIFNRHA-YEDDIEELFRKVIMKFR - - - - ETHDEQMPCK - - ERTTLCKKFYL \\
\hline CASc2 & 345 & DMICGFATLKGFSTAAMRNTKKGSWFIQELNTAIRQRA-NNTHLSDILVQVNGQIK- - - SREGYAPGSAHHRCKEMSEFTSSLCKDLYL \\
\hline CASc9 & 355 & 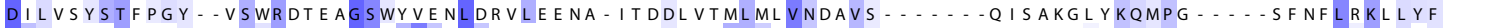 \\
\hline CASc8a & 398 & 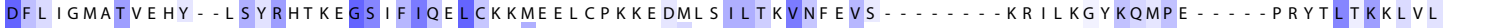 \\
\hline CASc8b & 248 & DFLFAIATVEHF - - RSYRHITNGSIFIQVLCKQLERGCAQKKDILSILTAVNGVVG . . - S S ILQGYKQMPE . - VRYTLTKALVL \\
\hline CASc10 & 428 & DYLMAMSTVPWY - ASYRDKSKGTWFIQSLCDNLRLLVPRGNDLLSILTKVNADVS - - - KKSDKSGLKKQMPQ - - PEFSLTRTVVF \\
\hline $\mathrm{ASc} 20$ & 267 & DFL I ARSTTDGH - - VSYRKPDEGSWF I QSLCRNLEKHCPLGADILTILLSVNNEVS . . . . . I QGLHSKQMPV . . - HEVAMRMKLIL \\
\hline Asc & 282 & DFL IARSTVEGY - V VSIRDETRGTWF IQSLCENLKEGSKRGHDILTILTKVNNDVSLKEGYLEVKNEIVDAKVTPQ⿻..PIFTLRKLLIF \\
\hline CASc3a & 197 & DFLYAYSTVPGY - YSWRNTMTGSWFIQSLCEMMTKYG - SELELLQIMTRVNHKVALDFESTSNMPGFDAKKQIPC - - IVSMLTKEMYF \\
\hline CASc3b & 200 & DFLYAYSTAPGY - Y AWRNVANGSWF ISSLCDMLLKYG - KQLEIMQVMTRVNHKVALEFESSSNLPGFDGKKQIPC - . IVSMLTKELYF \\
\hline ç & 210 & DF I MCYSVAEGY - - YS HRETVNGSWY IQDLCE ILRRYG - SELEFAEILTLVNRKVSLRSVLNCKDRSAVGKKQVPC . . - FASMLTKKLFF \\
\hline CASc & 171 & DF IMCYSTAEGF- - CSFREPLNGSWYIQDLCEILGRYH-SELQFTDILTLVNMKVSLRSVPNCRNRAAIGKKQMPC. \\
\hline CASc6c & 172 & DF IMCYSTAEGF- - CSFRDPLNGSWYIQDLCEILGRYR -SQLEFTNILTLVNRKVSLRSI - CDDLSATGTKQMPC - - FASMLTKRLFF \\
\hline Sc7 & 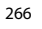 & DFLFAYSTVPGY - YSWRNPGRGSWFVQALCNVLSEFG-KQLEIMQILTRVNYMVATSFESWSEDPRFSEKKQIPC. \\
\hline CASc21 & 176 & DFLCCYSTVEGY - FAWRNPETGSIF|RELCKTLMD- - CRLEIIQILTRVNHLVAYCFQSYTLELETNRKRQMPC \\
\hline & & E I T KLLTRLNHQVAYNFQ - ARGKILGGKKQMPC. \\
\hline
\end{tabular}

Fig 3. Multiple protein sequence alignment of zebrafish caspase CASc catalytic domains. Residues highlighted in blue are conserved across caspases.

https://doi.org/10.1371/journal.pone.0197966.g003

new gene after duplication in teleosts. In addition to casp20, we discovered a previously unknown caspase on chromosome 5 that we named casp22 (Fig 2, Table 2). Surprisingly, we could not identified any casp22 ortholog in other teleost genomes. Analysis of the chromosomal synteny around the casp22 locus revealed a partial conservation among teleosts, with casp22 neighboring genes being dispersed on different chromosomes in species other than zebrafish (data not shown). Like Caspase-20, Caspase-22 possesses a CARD in its N-terminal region (Fig 1). Phylogenetic analysis revealed that casp20 and casp22 segregate together (Fig 2), suggesting they might originate from a duplication event unique to the zebrafish lineage.

The last classical functional group of caspases in vertebrates includes apoptosis executioners Caspases-3, -6 and -7 that are characterized by a short pro-domain. Another caspase sharing a similar structure, Caspase-17, has been identified in vertebrates other than therian mammals [16], but its function in programmed cell death has not been defined. We identified two orthologs for caspase-3 (casp3a and casp3b), three orthologs for caspase-6 (casp6a, casp6b and 


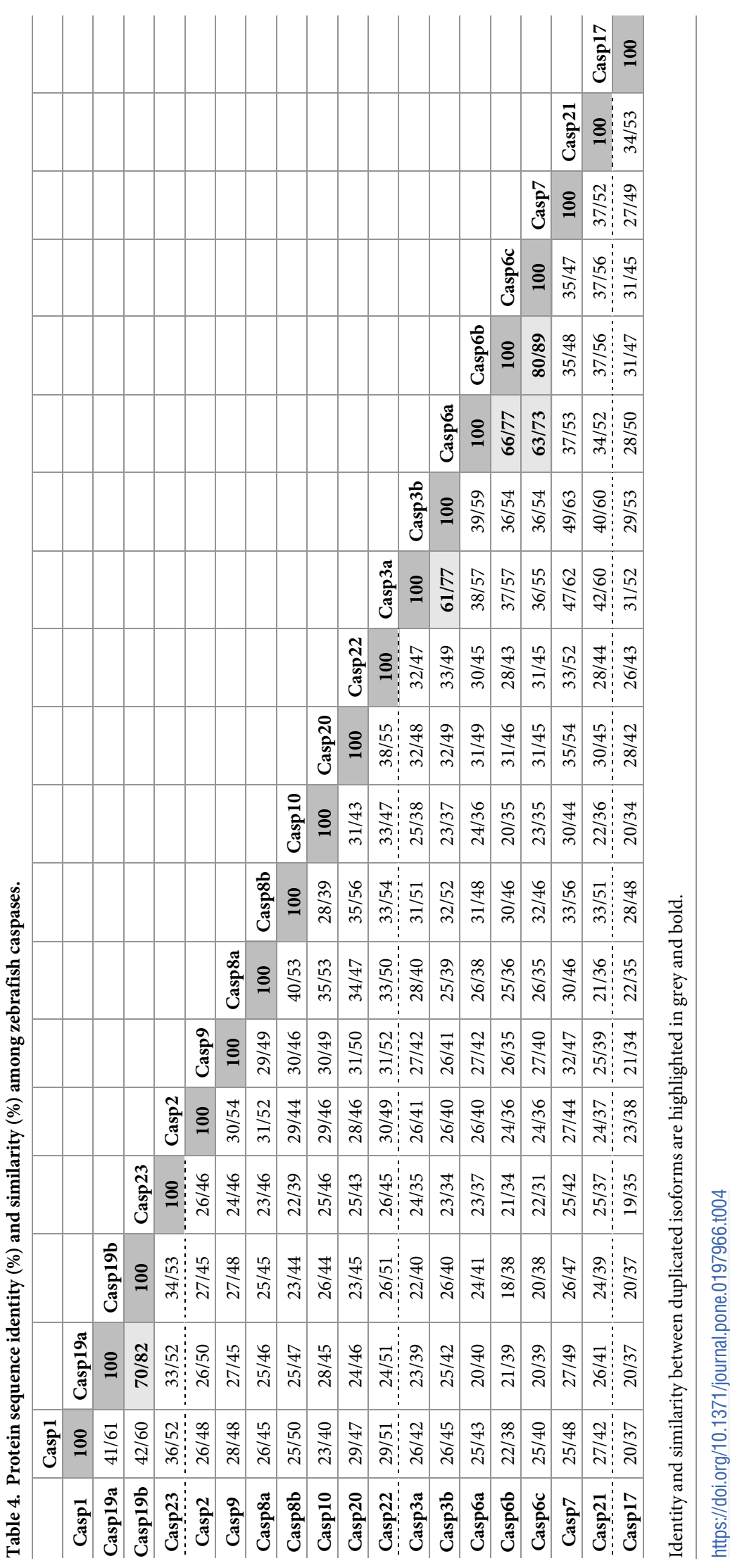


casp6c), and one ortholog each for caspase-7 (casp7) and caspase-17 (casp17) (Fig 2 and Table 3). We also discovered a novel uncharacterized caspase on chromosome 21 that we named casp21 (Table 2). Protein sequence comparison revealed a high level of conservation between human and zebrafish Caspase-3, -6 and -7 (Table 3). Casp $3 a$ and casp $3 b$ are located on different chromosomes, suggesting they have arisen from the whole genome duplication that occurred in the teleost lineage [66]. Supporting that hypothesis, several casp3 genes were also found on different chromosomes in medaka and stickleback and clustered in two distinct groups in our phylogenetic analysis (Fig 2). We could only identify one casp3 in fugu and tetraodon, suggesting a specific gene loss in the pufferfish lineage. In contrast to casp $3 a$ and casp $3 b$, casp $6 a$, casp $6 b$ and casp $6 c$ were found in adjacent positions on chromosome 3. Interestingly, we only identified one casp6 gene in stickleback, fugu or tetraodon, but three potential casp6 paralogs on independent scaffolds in medaka. Phylogenetic analysis showed that zebrafish and medaka casp6 paralogs cluster in separate groups, suggesting independent gene duplication events in these two lineages. Analysis of the chromosomal synteny at the casp6 locus further revealed a conservation of casp 6 flanking genes among teleosts except in zebrafish, suggesting extensive chromosomal rearrangements in addition to duplications (S2 Fig). Interestingly, the three zebrafish Caspase-6s share a Traf2 (TNF receptor associated factor 2) binding site in their pro-domain that is also found in Caspases- $8 \mathrm{a},-8 \mathrm{~b}$ and $-2 \mathrm{but}$ not in other executioner caspases (Fig 1), suggesting they might participate in the regulation of tumor necrosis factor (TNF) signaling. As reported previously [16], we also identified casp17 as a distinct caspase that does not phylogenetically segregate with the group of executioner caspases (Fig 2).

Remarkably, Caspase-17 has a Met in its CASc domain at position 197 instead of the Arg conserved in all other caspases that is involved in substrate binding (Fig 3). Finally, we discovered a novel caspase, Caspase-21, that segregates with the group defined by Caspases- 3 and -7 in our phylogenetic analysis (Fig 2). Casp21 appears specific to the zebrafish lineage, as we could not identify any casp 21 ortholog in other teleost genomes. Protein sequence comparison between Caspase-21 and the other zebrafish caspases further showed a higher similarity with Caspase-3a and Caspase-3b (Table 4), suggesting they might share common functional properties.

\section{Spatiotemporal expression of caspases during development}

To characterize the expression of caspases during development, we analyzed the temporal and spatial expression of all caspase genes from cleavage to larval stages using reverse transcription PCR (RT-PCR) and in situ hybridization (ISH).

Inflammatory caspases. RT-PCR analysis revealed that casp1, casp 19a, casp $19 b$ and casp23 have different temporal expression profiles during development (Fig 4). Expression of casp 1 and casp $19 a$ begins at the pharyngula stage ( $24 \mathrm{hpf}$ ) and is maintained at 48,72 and 96 hpf. In contrast, casp $19 b$ expression was only weakly detected at 48 and $72 \mathrm{hpf}$ and became clearly visible at $96 \mathrm{hpf}$. Remarkably, casp 23 expression could only be detected at cleavage and sphere stages, indicating that casp23 is only maternally expressed. ISH further revealed common and specific expression domains for casp 1 and casp19a at 48, 72 and $96 \mathrm{hpf}$ (Fig 5). While both caspases were detected in the pharyngeal arches as previously described [56], casp 1, but not casp 19a, was also found in the intestinal bulb at 72 and $96 \mathrm{hpf}$ (Fig 5C, 5D, 5G and 5H). In contrast, casp $19 a$ was specifically detected in the epidermis at 48 and $72 \mathrm{hpf}$ as well as in the proctodeum at $48 \mathrm{hpf}$ (Fig 5J-5O), suggesting distinct functions in these specific organs. Casp19a expression became notably restricted to the pharyngeal arches at $96 \mathrm{hpf}$ (Fig 5L and $5 \mathrm{P})$. Our attempts to detect casp $19 b$ with probes directed against the coding sequence or the 


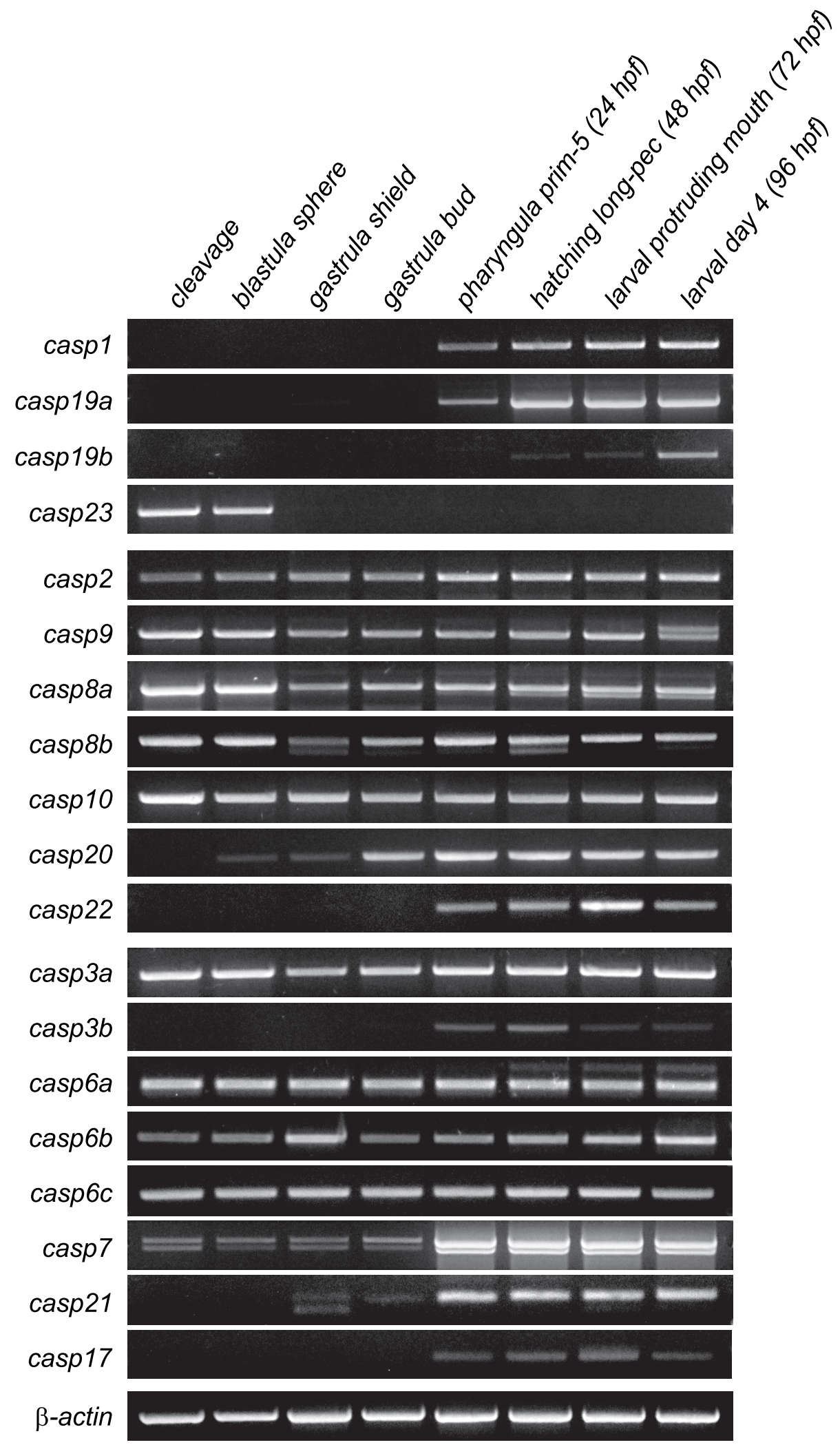

Fig 4. Temporal mRNA expression of caspases during embryonic development. RT-PCR was performed for all 19 caspase genes using cDNA from specified developmental stages. $\beta$-actin was used as a control.

https://doi.org/10.1371/journal.pone.0197966.g004 

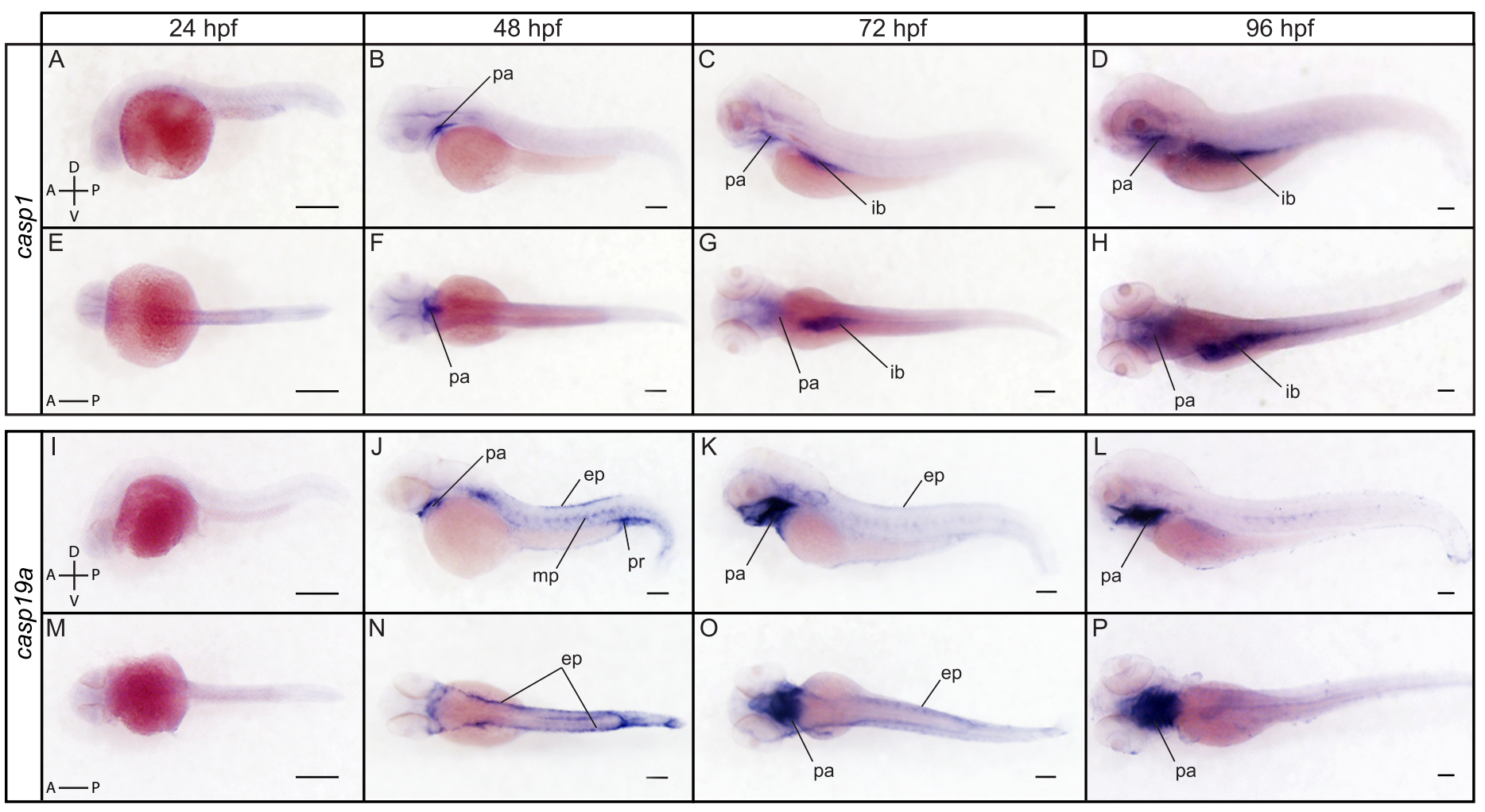

Fig 5. Spatial expression of casp1 and casp19a at 24, 48, 72 and $96 \mathrm{hpf}$. Lateral (A-D) and dorsal (E-H) views of whole embryos stained for casp 1 by ISH show expression in the pharyngeal arches (pa) at 48,72 and $96 \mathrm{hpf}$ and in the intestinal bulb (ib) at 72 and $96 \mathrm{hpf}$. Casp 19a expression is strongly detected in the pharyngeal arches (pa) at 48, 72 and $96 \mathrm{hpf}$, and is also seen in the epidermis (ep) at 48 and $72 \mathrm{hpf}$ (lateral views in J and $\mathrm{K}$, dorsal views in $\mathrm{N}$ and $\mathrm{O}$ ). Expression is also observed in the proctodeum (pr) and at lower levels in the muscles pioneers (mp) at $48 \mathrm{hpf}$. Scale bar: $200 \mu \mathrm{m}$.

https://doi.org/10.1371/journal.pone.0197966.g005

5'UTR of the transcript were unfortunately unsuccessful, suggesting that casp $19 b$ expression levels might be below the detection threshold of ISH.

\begin{tabular}{|l|l|l|l|l|}
\hline \multicolumn{2}{|c|}{$24 \mathrm{hpf}$} & $48 \mathrm{hpf}$ & & \\
\hline \\
\hline
\end{tabular}

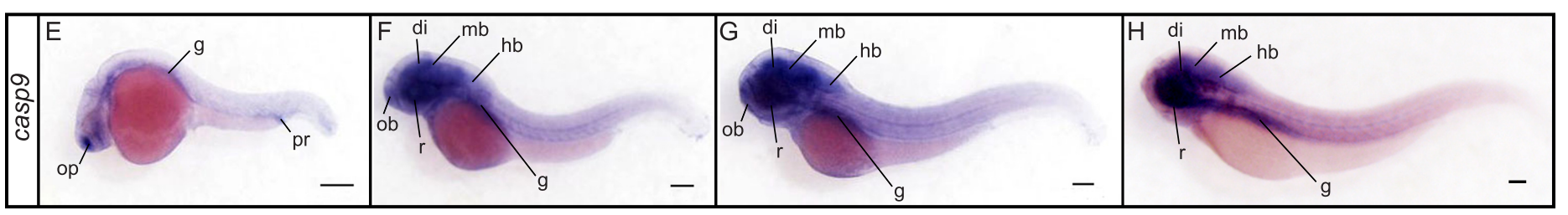

Fig 6. Spatial expression of casp2 and casp 9 at $24,48,72$ and 96 hpf. Lateral views of whole embryos stained for casp 2 (A-D) and casp 9 (E-H) by ISH. Casp2 is expressed in the midbrain ( $\mathrm{mb})$ and hindbrain $(\mathrm{hb})$ at all stages analyzed. Expression is also observed in the pharyngeal arches (pa) and retina (r) at 48, 72 and $96 \mathrm{hpf}$ (B-D), and in the intestinal bulb (ib) at 72 and $96 \mathrm{hpf}(\mathrm{C}, \mathrm{D})$. Casp 2 becomes strongly detected in the liver (lv) at 96 hpf (D). Casp9 is expressed at high levels in the olfactory placodes (op) and at lower levels in the gut (g) and proctodeum (pr) at $24 \mathrm{hpf}(\mathrm{E})$. Casp 9 appears ubiquitously expressed at low levels at 48 and $72 \mathrm{hpf}$ and is strongly detected in the retina, diencephalon (di), midbrain, hindbrain and gut from 48 to $96 \mathrm{hpf}$ (F-H). Scale bar: $200 \mu \mathrm{m}$.

https://doi.org/10.1371/journal.pone.0197966.g006 

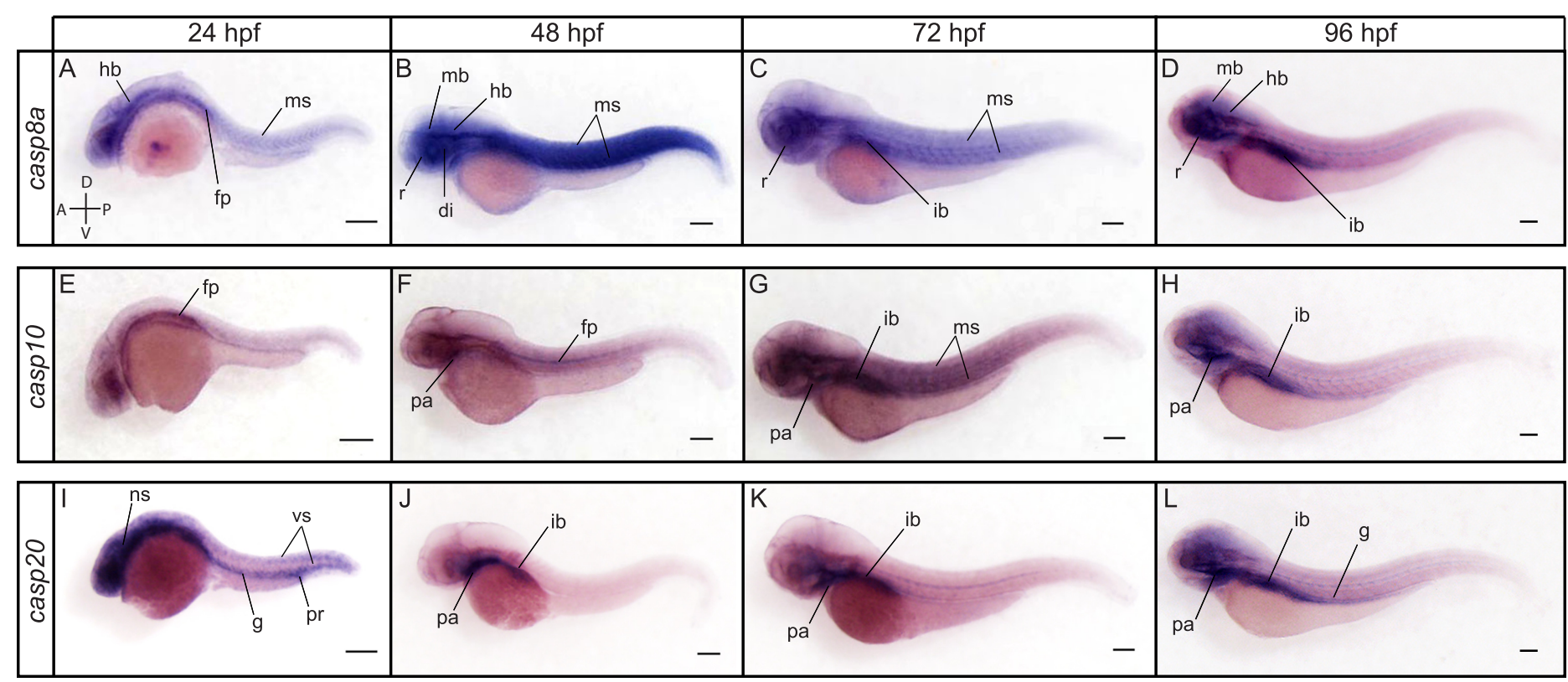

Fig 7. Spatial expression of the caspase-8 family members casp8a, casp10 and casp20 at 24, 48, 72 and 96 hpf. Lateral views of whole embryos stained for casp8a (A-D), casp10 (E-H) and casp20 (I-L) by ISH. Casp8a is expressed in the hindbrain (hb), muscles (ms) and at the floorplate (fp) at $24 \mathrm{hpf}$ (A). Its expression is then strongly detected in the retina (r), diencephalon (di), midbrain (mb), hindbrain and muscles (ms) at $48 \mathrm{hpf}(\mathrm{B})$. Additional expression in the intestinal bulb (ib) is observed at 72 and $96 \mathrm{hpf}(\mathrm{C}, \mathrm{D})$. Casp10 expression is detected at the floorplate at 24 and $48 \mathrm{hpf}(\mathrm{E}, \mathrm{F})$ and in the pharyngeal arches (pa) at $48 \mathrm{hpf}(\mathrm{F})$. A strong expression is detected in the pharyngeal arches, muscles and intestinal bulb at $72 \mathrm{hpf}(\mathrm{G})$. Casp10 remains highly detected in the pharyngeal arches and intestinal bulb at $96 \mathrm{hpf}(\mathrm{H})$. Casp20 is strongly expressed in the nervous system (ns), vascular system (vs), proctodeum (pr) and throughout the gut (g) at $24 \mathrm{hpf}(\mathrm{I})$. Its expression becomes restricted to the pharyngeal arches and the intestinal bulb at 48, 72 and $96 \mathrm{hpf}(\mathrm{J}-\mathrm{L})$. Scale bar: $200 \mu \mathrm{m}$.

https://doi.org/10.1371/journal.pone.0197966.g007

Initiator caspases. Initiator caspases including casp2, casp9, and the members of the caspase- 8 subfamily casp $8 a$, casp $8 b$, casp 10 , casp 20 and casp 22 share a similar temporal expression profile during development, as shown by RT-PCR (Fig 4). Expression of casp2, casp9, casp8a, casp $8 b$ and casp 10 was detected throughout embryonic development from cleavage to larval stages, indicating both maternal and zygotic expression. Casp $8 a$ and casp $8 b$ expression appeared notably stronger at maternal stages, suggesting an important function for these caspases during early development. Casp20 expression was not detected at cleavage stage but was observed at very low levels at sphere and shield stages. It was then strongly detected from bud stage to $96 \mathrm{hpf}$. In contrast, Casp22 expression was only observed at lower levels from 24 to 96 hpf.

ISH revealed distinct expression patterns for casp 2 and casp 9 from 24 to 96 hpf (Fig 6). While casp 2 appeared selectively expressed in the midbrain and hindbrain at $24 \mathrm{hpf}$ (Fig 6A), casp 9 expression was strongly detected in the olfactory placode and was observed at lower levels in the gut and proctodeum (Fig 6D). Casp 2 continued to be expressed in the midbrain and hindbrain at 48 and $72 \mathrm{hpf}$ and was also detected in the retina and pharyngeal arches at these stages (Fig 6B and 6C). Expression in the intestinal bulb appeared at $72 \mathrm{hpf}$ (Fig 6C). Compared to casp2, casp 9 appeared ubiquitously expressed at low levels at 48 and $72 \mathrm{hpf}$ (Fig 6E and 6F). Stronger expression was detected in the retina and different regions of the brain including the diencephalon, midbrain and hindbrain, which is consistent with the reported role of Caspase-9 in retinal axon arbor dynamics [38]. At $96 \mathrm{hpf}$, casp 2 and casp 9 became more similarly expressed and were strongly detected in the intestinal bulb, the nervous system and the retina (Fig $6 \mathrm{D}$ and $6 \mathrm{H}$ ). Casp2, but not casp9, was notably observed in the liver at that stage (Fig 6D). 

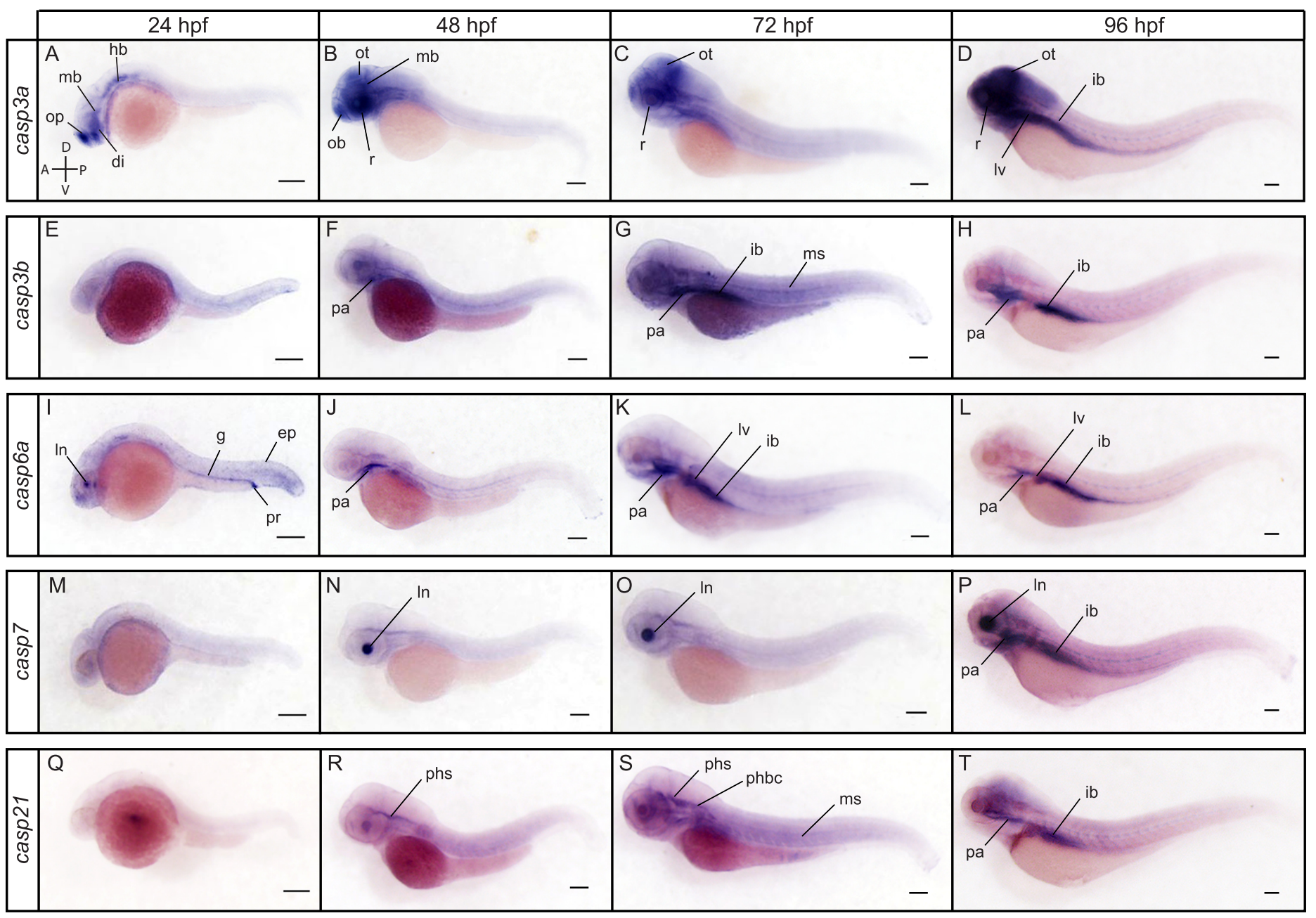

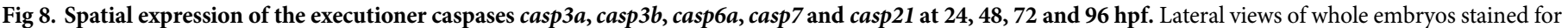

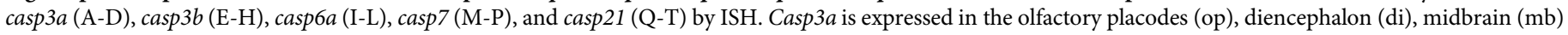

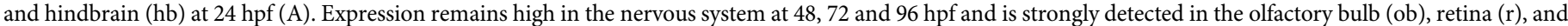

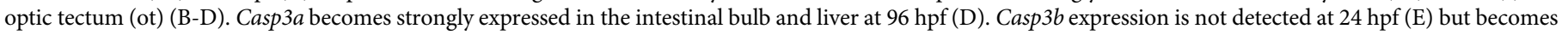

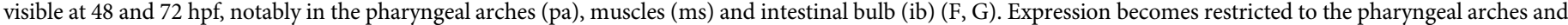

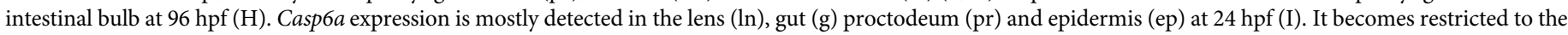

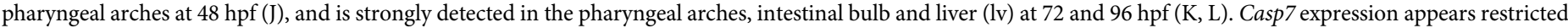

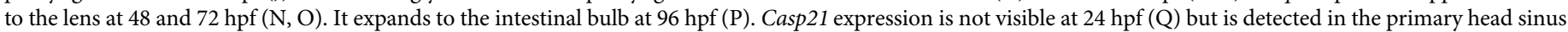
(phs) at $48 \mathrm{hpf}(\mathrm{R})$. It is maintained in the primary head sinus and is also observed in the primordial hindbrain channel (phbc) and the muscles at $72 \mathrm{hpf}(\mathrm{S})$. Casp21 expression becomes visible in the nervous system, pharyngeal arches and intestinal bulb at 96 hpf (T). Scale bar: $200 \mu \mathrm{m}$.

Members of the caspase- 8 subfamily demonstrated a different spatial expression compared to casp2 and casp9 (Fig 7). While we were unable to detect casp $8 b$ and casp22 despite using multiple probes directed against the coding sequence, 3'UTR, or 5'UTR of both transcripts, we observed a strong expression of casp $8 a$ in the muscles, retina and nervous system at 24,48 and $72 \mathrm{hpf}$ (Fig 7A-7C). Casp8a expression decreased in the muscles but remained high in the nervous system and retina at $96 \mathrm{hpf}$ and became prominent in the intestinal bulb (Fig 7D). Casp10 appeared to be expressed at lower levels and was notably detected at the floorplate at 24 and 48 hpf (Fig 7E and 7F). Its expression became apparent in the pharyngeal arches at 48 and $72 \mathrm{hpf}$ (Fig $7 \mathrm{~F}$ and $7 \mathrm{G}$ ) and was strongly detected in the muscles and intestinal bulb at $72 \mathrm{hpf}$ (Fig $7 \mathrm{G})$. Similarly to casp $8 a$, casp 10 expression decreased in the muscles and became strongly 


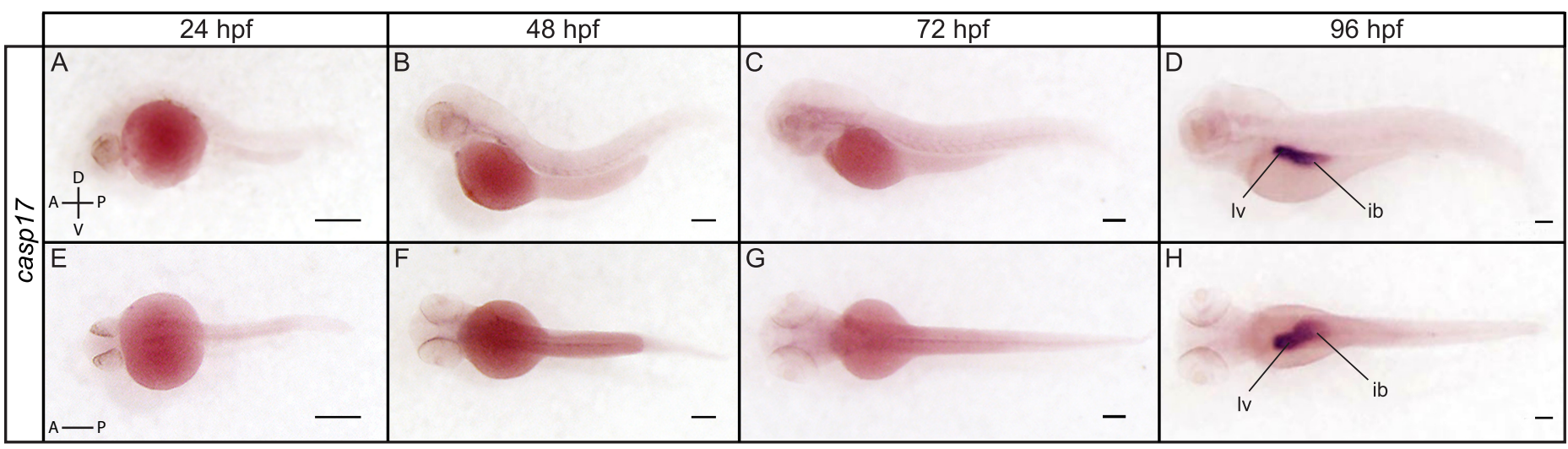

Fig 9. Spatial expression of casp17 at 24, 48, 72 and 96 hpf. Lateral (A-D) and dorsal (E-H) views of a whole embryo stained for casp17 by ISH show a strong and specific expression of casp17 in the liver (lv) and intestinal bulb (ib) at $96 \mathrm{hpf}$ (D, H). Scale bar: $200 \mu \mathrm{m}$.

https://doi.org/10.1371/journal.pone.0197966.g009

detected in the intestinal bulb at $96 \mathrm{hpf}$ (Fig 7H). In contrast to the low expression of casp 10 at $24 \mathrm{hpf}$, casp 20 was strongly detected in the nervous system, throughout the gut and in the proctodeum at that stage (Fig 7I). Interestingly, casp20 expression was also observed in the vascular system at this time point. At $48 \mathrm{hpf}$, however, casp20 expression became restricted to the pharyngeal arches and the intestinal bulb (Fig 7J), where it remained strongly detected at 72 and $96 \mathrm{hpf}$ (Fig 7K and 7L).

Executioner caspases. Known as the principal mediators of apoptosis in all tissues, executioner caspases appeared to have variable spatiotemporal patterns of expression during development. Casp $3 a$, casp $6 a$, casp $6 b$ and casp $6 c$ were detected at relatively constant levels from maternal to late stages of development by RT-PCR (Fig 4). In contrast, only low levels of expression were observed for casp $3 b$ and casp 17 from 24 to 96 hpf. Casp 7 expression was detected at low levels from cleavage to bud stages but increased from 24 to $96 \mathrm{hpf}$. Interestingly, a shorter casp 7 transcript was detected at all stages by RT-PCR and appeared to encode a protein with a shorter pro-domain. The functional significance of this isoform remains however unclear. Casp 21 was barely detected at shield and bud stages but became clearly expressed from 24 to $96 \mathrm{hpf}$.

ISH analysis revealed specific and complementary expression patterns of executioner caspases at 24, 48, 72 and $96 \mathrm{hpf}$ (Fig 8). While casp $3 b$ could not be clearly detected at $24 \mathrm{hpf}$ (Fig $8 \mathrm{E})$, strong expression of casp $3 a$ was observed in the olfactory placodes, diencephalon, midbrain and hindbrain at that stage (Fig 8A). As reported in previous studies [38], casp3a remained strongly expressed in the brain and retina at 48,72 and $96 \mathrm{hpf}$, but was not detected in the trunk (Fig 8B-8D). In contrast, casp3b appeared ubiquitously expressed, albeit at low levels, at $48 \mathrm{hpf}$, with a higher expression in the pharyngeal arches (Fig 8F). Expression levels appeared to increase at $72 \mathrm{hpf}$, being higher in the pharyngeal arches, muscles and intestinal bulb (Fig 8G). Both casp $3 a$ and casp $3 b$ became expressed at high levels in the intestinal bulb at $96 \mathrm{hpf}$ (Fig 8D and 8H). While we have not been able to detect casp $6 b$ and cas $6 c$, we observed a specific and dynamic expression of casp6a at 24, 48, 72 and 96 hpf. Casp6a expression was detected in the lens, gut, proctodeum and to a lower extent in the epidermis at $24 \mathrm{hpf}$ (Fig 8I). It became restricted to the pharyngeal arches at $48 \mathrm{hpf}$ (Fig 8J), but then expanded and was strongly visible in the liver and intestinal bulb at 72 and $96 \mathrm{hpf}$ (Fig 8K and 8L). While casp3a, casp $3 b$ and cas $6 a$ are expressed in several tissues and organs, casp 7 was exclusively detected in the lens at 48 and $72 \mathrm{hpf}$ (Figs $8 \mathrm{~N}$ and $8 \mathrm{O}$ ). Although surprising, such restricted expression has also been observed in the salmon embryo [67], suggesting a highly specific and conserved 
Table 5. Developmental expression patterns of zebrafish caspases.

\begin{tabular}{|c|c|c|c|c|c|c|c|c|c|c|c|c|c|c|c|c|c|c|}
\hline & & & ep & op/ob & di & $\mathrm{mb}$ & hb & $\mathrm{fp}$ & r & $\ln$ & $\mathrm{mp} / \mathrm{ms}$ & phs/phbc & vs & pa & lv & ib & $\mathrm{g}$ & pr \\
\hline \multirow[t]{8}{*}{ INFLAMMATORY } & \multirow[t]{4}{*}{ caspl } & $24 \mathrm{hpf}$ & & & & & & & & & & & & & & & & \\
\hline & & $48 \mathrm{hpf}$ & & & & & & & & & & & & +++ & & & & \\
\hline & & $72 \mathrm{hpf}$ & & & & & & & & & & & & +++ & & +++ & & \\
\hline & & $96 \mathrm{hpf}$ & & & & & & & & & & & & +++ & & +++ & & \\
\hline & \multirow[t]{4}{*}{ casp19a } & $24 \mathrm{hpf}$ & & & & & & & & & & & & & & & & \\
\hline & & $48 \mathrm{hpf}$ & +++ & & & & & & & & +++ & & & +++ & & & & +++ \\
\hline & & $72 \mathrm{hpf}$ & + & & & & & & & & & & & +++ & & & & \\
\hline & & $96 \mathrm{hpf}$ & & & & & & & & & & & & +++ & & & & \\
\hline \multirow[t]{20}{*}{ INITIATOR } & \multirow[t]{4}{*}{ casp2 } & $24 \mathrm{hpf}$ & & & & ++ & ++ & & & & & & & & & & & \\
\hline & & $48 \mathrm{hpf}$ & & & & ++ & ++ & & ++ & & & & & ++ & & & & \\
\hline & & $72 \mathrm{hpf}$ & & & & +++ & +++ & & +++ & & & & & ++ & & +++ & & \\
\hline & & $96 \mathrm{hpf}$ & & & & +++ & +++ & & +++ & & & & & +++ & +++ & +++ & + & \\
\hline & \multirow[t]{4}{*}{ casp9 } & $24 \mathrm{hpf}$ & & +++ & & & & & & & & & & & & & +++ & +++ \\
\hline & & $48 \mathrm{hpf}$ & & +++ & +++ & +++ & +++ & & +++ & & + & & & & & & +++ & \\
\hline & & $72 \mathrm{hpf}$ & & +++ & +++ & +++ & +++ & & +++ & & + & & & & & & +++ & \\
\hline & & $96 \mathrm{hpf}$ & & & ++ & ++ & ++ & & +++ & & & & & + & & ++ & ++ & \\
\hline & \multirow[t]{4}{*}{ casp $8 a$} & $24 \mathrm{hpf}$ & & & + & + & +++ & +++ & + & & + & & & & & & & \\
\hline & & $48 \mathrm{hpf}$ & & & +++ & +++ & +++ & & +++ & & +++ & & & & & & & \\
\hline & & $72 \mathrm{hpf}$ & & & & + & + & & +++ & & +++ & & & & & +++ & & \\
\hline & & $96 \mathrm{hpf}$ & & & & ++ & ++ & & +++ & & & & & ++ & & +++ & & \\
\hline & \multirow[t]{4}{*}{ casp10 } & $24 \mathrm{hpf}$ & & & & & & ++ & & & & & & & & & & \\
\hline & & $48 \mathrm{hpf}$ & & & & & & & & & + & & & +++ & & & & \\
\hline & & $72 \mathrm{hpf}$ & & & & 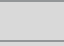 & & & & & +++ & & & +++ & & +++ & & \\
\hline & & $96 \mathrm{hpf}$ & & & & ++ & ++ & & & & & & & +++ & & ++ & & \\
\hline & \multirow[t]{4}{*}{ casp20 } & $24 \mathrm{hpf}$ & & +++ & +++ & +++ & +++ & & & & & & ++ & & & & +++ & +++ \\
\hline & & $48 \mathrm{hpf}$ & & & & & & & & & & & & +++ & & +++ & & \\
\hline & & $72 \mathrm{hpf}$ & & & & & & & & & & & & +++ & & +++ & & \\
\hline & & $96 \mathrm{hpf}$ & & & ++ & ++ & ++ & & & & & & & +++ & & +++ & + & \\
\hline \multirow[t]{20}{*}{ EXECUTIONER } & \multirow[t]{4}{*}{ casp $3 a$} & $24 \mathrm{hpf}$ & & +++ & +++ & +++ & +++ & & & & & & & & & & & \\
\hline & & $48 \mathrm{hpf}$ & & +++ & +++ & +++ & ++ & & +++ & & & & & & & & & \\
\hline & & $72 \mathrm{hpf}$ & & ++ & +++ & +++ & ++ & & +++ & & & & & & & & & \\
\hline & & $96 \mathrm{hpf}$ & & ++ & +++ & +++ & ++ & & +++ & & & & & & +++ & ++ & ++ & \\
\hline & \multirow[t]{4}{*}{ casp3b } & $24 \mathrm{hpf}$ & & & & & & & & & & & & & & & & \\
\hline & & $48 \mathrm{hpf}$ & & & & & & & & & + & & & + & & & & \\
\hline & & $72 \mathrm{hpf}$ & & & & & & & & & ++ & & & ++ & & +++ & & \\
\hline & & $96 \mathrm{hpf}$ & & & & & & & & & & & & ++ & & +++ & & \\
\hline & \multirow[t]{4}{*}{ casp6a } & $24 \mathrm{hpf}$ & + & & & & & & & ++ & & & & & & & +++ & +++ \\
\hline & & $48 \mathrm{hpf}$ & & & & & & & & & & & & +++ & & & & \\
\hline & & $72 \mathrm{hpf}$ & & & & & & & & & + & & & +++ & +++ & +++ & & \\
\hline & & $96 \mathrm{hpf}$ & & & & & & & & & & & & + & ++ & +++ & & \\
\hline & \multirow[t]{4}{*}{ casp7 } & $24 \mathrm{hpf}$ & & & & & & & & & & & & & & & & \\
\hline & & $48 \mathrm{hpf}$ & & & & & & & & +++ & & & & & & & & \\
\hline & & $72 \mathrm{hpf}$ & & & & & & & & +++ & & & & & & & & \\
\hline & & $96 \mathrm{hpf}$ & & & & & & & & +++ & & & & +++ & & +++ & & \\
\hline & \multirow[t]{4}{*}{ casp21 } & $24 \mathrm{hpf}$ & & & & & & & & & & & & & & & & \\
\hline & & $48 \mathrm{hpf}$ & & & & & & & & & + & + & & & & & & \\
\hline & & $72 \mathrm{hpf}$ & & & & & & & & & + & +++ & & & & & & \\
\hline & & $96 \mathrm{hpf}$ & & & & + & + & & & & & & & ++ & & ++ & & \\
\hline
\end{tabular}

(Continued) 
Table 5. (Continued)

\begin{tabular}{|c|c|c|c|c|c|c|c|c|c|c|c|c|c|c|c|c|c|c|}
\hline & & & ep & op/ob & di & $\mathrm{mb}$ & hb & $\mathrm{fp}$ & $\mathbf{r}$ & $\ln$ & $\mathrm{mp} / \mathrm{ms}$ & phs/phbc & vs & pa & lv & ib & $\mathrm{g}$ & pr \\
\hline \multirow[t]{4}{*}{ OTHER } & \multirow[t]{4}{*}{ casp17 } & $24 \mathrm{hpf}$ & & & & & & & & & & & & & & & & \\
\hline & & $48 \mathrm{hpf}$ & & & & & & & & & & & & & & & & \\
\hline & & $72 \mathrm{hpf}$ & & & & & & & & & & & & & & & & \\
\hline & & $96 \mathrm{hpf}$ & & & & & & & & & & & & & +++ & +++ & & \\
\hline
\end{tabular}

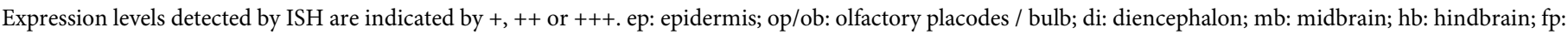

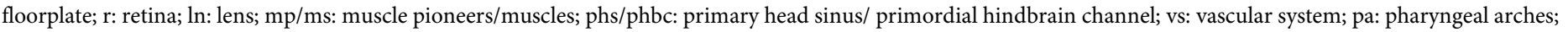
lv: liver; ib: intestinal bulb; g: gut; pr: proctodeum.

https://doi.org/10.1371/journal.pone.0197966.t005

function among teleosts. Like casp $3 a$, casp $3 b$ and casp $6 a$, casp 7 expression became also detected in the intestinal bulb at $96 \mathrm{hpf}$ (Fig 8P). Casp21 expression was not detected at $24 \mathrm{hpf}$ (Fig $8 \mathrm{O}$ ) but became visible in the primary head sinus (phs) at $48 \mathrm{hpf}$ (Fig 8R). Expression was maintained in the phs at $72 \mathrm{hpf}$ and became also visible in the primordial hindbrain channel and the muscles (Fig 8S). It became detected in the pharyngeal arches and intestinal bulb at 96 hpf (Fig 8T). Finally, casp 17 expression could not be observed by ISH at 24, 48 or $72 \mathrm{hpf}$ (Fig 9A, 9C, 9E and 9G) but was strongly and exclusively detected in the liver and intestinal bulb at $96 \mathrm{hpf}$ (Fig 9D and 9H). Previous studies have also detected casp17 in the liver of chicken [16], suggesting functional conservation among vertebrates.

\section{Conclusions}

Our study reveals that the zebrafish caspase family is much larger than anticipated, including 19 distinct caspase genes. As summarized in Table 5, zebrafish caspases have both shared and specific expression profiles that suggest distinct and complementary functions during development. It is interesting to note that only a restricted number of caspases including casp2, casp3a, casp $8 a$, casp 9 and casp 20 are strongly expressed in the developing nervous system. Other caspases may not be expressed there or may be expressed at such low levels in normal conditions that they would escape detection by ISH. We also discovered that some caspases such as casp6a or casp $19 a$ have dynamic expression patterns that change over time, while others such as casp7 are unexpectedly expressed in a restricted number of structures or tissues. Altogether, our analysis offers a starting point for future studies investigating the functions of caspases during embryonic development. Our characterization of zebrafish caspases will be especially useful for the generation of new caspase mutants or the development of genetically encoded biosensors expressed in a cell- or tissue-specific manner.

\section{Supporting information}

S1 Fig. Syntenic conservation between casp8, casp10, casp18 and casp20 orthologs. Caspase genes are represented in red. Genes conserved among coelacanth and tetrapods are represented in green while genes conserved among teleosts are shown in blue. Non-conserved genes are in white. Chromosomes are indicated on the left for each species, with zebrafish chromosomes highlighted in grey. Hs: Homo sapiens, Gg: Gallus gallus; Lc: Latimeria chalumnae, Dr: Danio rerio, Tr: Takifugu rubripes, Ga: Gasterosteus aculeatus, Ol: Oryzias latipes. (EPS)

S2 Fig. Syntenic conservation between casp6 orthologs. Caspase-6 genes are represented in red. Genes conserved among coelacanth and tetrapods are represented in green while those conserved among teleosts are shown in blue. Non-conserved genes are in white. Chromosomes are indicated on the left for each species, with zebrafish chromosomes highlighted in grey. Hs: 
Homo sapiens, Gg: Gallus gallus; Lc: Latimeria chalumnae, Dr: Danio rerio, Tr: Takifugu rubripes, Ga: Gasterosteus aculeatus, Ol: Oryzias latipes, Tn: Tetraodon nigroviridis. (EPS)

\section{Acknowledgments}

We would like to thank Cory J. Weaver for his advice and comments on the manuscript and Brian Wheeler for technical assistance and excellent fish husbandry.

\section{Author Contributions}

Conceptualization: Fabienne E. Poulain.

Data curation: Olivia Spead, Tine Verreet, Cory J. Donelson, Fabienne E. Poulain.

Formal analysis: Olivia Spead, Tine Verreet, Cory J. Donelson, Fabienne E. Poulain.

Funding acquisition: Fabienne E. Poulain.

Investigation: Olivia Spead, Tine Verreet, Cory J. Donelson, Fabienne E. Poulain.

Project administration: Fabienne E. Poulain.

Resources: Fabienne E. Poulain.

Supervision: Fabienne E. Poulain.

Validation: Olivia Spead, Tine Verreet, Cory J. Donelson, Fabienne E. Poulain.

Visualization: Olivia Spead, Fabienne E. Poulain.

Writing - original draft: Olivia Spead, Fabienne E. Poulain.

Writing - review \& editing: Olivia Spead, Tine Verreet, Fabienne E. Poulain.

\section{References}

1. Alnemri ES, Livingston DJ, Nicholson DW, Salvesen G, Thornberry NA, Wong WW, et al. Human ICE/ CED-3 protease nomenclature. Cell. 1996; 87(2):171. PMID: 8861900

2. Mcllwain DR, Berger T, Mak TW. Caspase functions in cell death and disease. Cold Spring Harb Perspect Biol. 2013 5(4):a008656. https://doi.org/10.1101/cshperspect.a008656 PMID: 23545416

3. Fuchs $Y$, Steller H. Programmed cell death in animal development and disease. Cell. 2011; 147 (4):742-58. https://doi.org/10.1016/j.cell.2011.10.033 PMID: 22078876

4. Yamaguchi Y, Miura M. Programmed cell death in neurodevelopment. Dev Cell. 2015; 32(4):478-90. https://doi.org/10.1016/j.devcel.2015.01.019 PMID: 25710534

5. Kuida K, Zheng TS, Na S, Kuan C, Yang D, Karasuyama H, et al. Decreased apoptosis in the brain and premature lethality in CPP32-deficient mice. Nature. 1996; 384(6607):368-72. https://doi.org/10.1038/ 384368a0 PMID: 8934524

6. Hakem R, Hakem A, Duncan GS, Henderson JT, Woo M, Soengas MS, et al. Differential requirement for caspase 9 in apoptotic pathways in vivo. Cell. 1998; 94(3):339-52. PMID: 9708736

7. Kuida K, Haydar TF, Kuan CY, Gu Y, Taya C, Karasuyama H, et al. Reduced apoptosis and cytochrome c-mediated caspase activation in mice lacking caspase 9. Cell. 1998; 94(3):325-37. PMID: 9708735

8. Pompeiano M, Blaschke AJ, Flavell RA, Srinivasan A, Chun J. Decreased apoptosis in proliferative and postmitotic regions of the Caspase 3-deficient embryonic central nervous system. J Comp Neurol. 2000; 423(1):1-12. PMID: 10861532

9. Kuranaga E. Caspase signaling in animal development. Dev Growth Differ. 2011; 53(2):137-48. https://doi.org/10.1111/j.1440-169X.2010.01237.x PMID: 21338340

10. Hyman BT, Yuan J. Apoptotic and non-apoptotic roles of caspases in neuronal physiology and pathophysiology. Nat Rev Neurosci. 2012; 13(6):395-406. https://doi.org/10.1038/nrn3228 PMID: 22595785 
11. Connolly PF, Jäger R, Fearnhead HO. New roles for old enzymes: killer caspases as the engine of cell behavior changes. Front Physiol. 2014; 5:149. https://doi.org/10.3389/fphys.2014.00149 PMID: 24795644

12. Unsain N, Barker PA. New Views on the Misconstrued: Executioner Caspases and Their Diverse Nonapoptotic Roles. Neuron. 2015; 88(3):461-74. https://doi.org/10.1016/j.neuron.2015.08.029 PMID: 26539888

13. Fischer $\mathrm{H}$, Koenig $\mathrm{U}$, Eckhart $\mathrm{L}$, Tschachler $\mathrm{E}$. Human caspase 12 has acquired deleterious mutations. Biochem Biophys Res Commun. 2002; 293(2):722-6. https://doi.org/10.1016/S0006-291X(02)002899 PMID: 12054529

14. Xue Y, Daly A, Yngvadottir B, Liu M, Coop G, Kim Y. Spread of an inactive form of caspase-12 in humans is due to recent positive selection. Am J Hum Genet. 2006; 78(4):659-70. https://doi.org/10. 1086/503116 PMID: 16532395

15. Eckhart L, Ballaun C, Uthman A, Kittel C, Stichenwirth M, Buchberger M, et al. Identification and characterization of a novel mammalian caspase with proapoptotic activity. J Biol Chem. 2005; 280 (42):35077-80. https://doi.org/10.1074/jbc.C500282200 PMID: 16120609

16. Eckhart L, Ballaun C, Hermann M, VandeBerg JL, Sipos W, Uthman A, et al. Identification of novel mammalian caspases reveals an important role of gene loss in shaping the human caspase repertoire. Mol Biol Evol. 2008; 25(5):831-41. https://doi.org/10.1093/molbev/msn012 PMID: 18281271

17. Sakamaki K, Satou Y. Caspases: evolutionary aspects of their functions in vertebrates. J Fish Biol. 2009; 74(4):727-53. https://doi.org/10.1111/j.1095-8649.2009.02184.x PMID: 20735596

18. Pérez-Garijo A. When dying is not the end: Apoptotic caspases as drivers of proliferation. Semin Cell Dev Biol. 2017; pii: S1084-9521(17)30500-1.

19. Bell RAV, Megeney LA. Evolution of caspase-mediated cell death and differentiation: twins separated at birth. Cell Death Differ. 2017; 24(8):1359-1368. https://doi.org/10.1038/cdd.2017.37 PMID: 28338655

20. Burgon PG, Megeney LA. Caspase signaling, a conserved inductive cue for metazoan cell differentiation. Semin Cell Dev Biol. 2017; pii: S1084-9521(17)30111-8.

21. Keller N, Ozmadenci D, Ichim G, Stupack D. Caspase-8 function, and phosphorylation, in cell migration. Semin Cell Dev Biol. 2018; pii: S1084-9521(17)30529-3.

22. Salvesen GS, Walsh CM. Functions of caspase 8: the identified and the mysterious. Semin Immunol. 2014; 26(3):246-52. https://doi.org/10.1016/j.smim.2014.03.005 PMID: 24856110

23. Bergmann A, Steller H. Apoptosis, stem cells, and tissue regeneration. Sci Signal. 2010; 3(145):re8 https://doi.org/10.1126/scisignal.3145re8 PMID: 20978240

24. Hollville $E$, Deshmukh M. Physiological functions of non-apoptotic caspase activity in the nervous system. Semin Cell Dev Biol. 2017; pii: S1084-9521(17)30105-2.

25. Mukherjee A, Williams DW. More alive than dead: non-apoptotic roles for caspases in neuronal development, plasticity and disease. Cell Death Differ. 2017; 24(8):1411-1421. https://doi.org/10.1038/cdd. 2017.64 PMID: 28644437

26. Fernando $P$, Brunette $S$, Megeney LA. Neural stem cell differentiation is dependent upon endogenous caspase 3 activity. FASEB J. 2005; 19(12):1671-3. https://doi.org/10.1096/fj.04-2981fje PMID: 16103108

27. Oomman S, Strahlendorf H, Finckbone V, Strahlendorf J. Non-lethal active caspase-3 expression in Bergmann glia of postnatal rat cerebellum. Brain Res Dev Brain Res. 2005; 160(2):130-45. https://doi. org/10.1016/j. devbrainres.2005.07.010 PMID: 16226814

28. Oomman S, Strahlendorf H, Dertien J, Strahlendorf J. Bergmann glia utilize active caspase-3 for differentiation. Brain Res. 2006; 1078(1):19-34. PMID: 16700096

29. Dash PK, Blum S, Moore AN. Caspase activity plays an essential role in long-term memory. Neuroreport. 2000; 11(12):2811-6. PMID: 10976968

30. Gulyaeva NV, Kudryashov IE, Kudryashova IV. Caspase activity is essential for long-term potentiation. J Neurosci Res. 2003; 73(6):853-64. https://doi.org/10.1002/jnr.10730 PMID: 12949912

31. Stepanichev MY, Kudryashova IV, Yakovlev AA, Onufriev MV, Khaspekov LG, Lyzhin AA, et al. Central administration of a caspase inhibitor impairs shuttle-box performance in rats. Neuroscience. 2005; 136 (2):579-91. https://doi.org/10.1016/j.neuroscience.2005.08.010 PMID: 16198488

32. Huesmann GR, Clayton DF. Dynamic role of postsynaptic caspase-3 and BIRC4 in zebra finch songresponse habituation. Neuron. 2006; 52(6):1061-72. https://doi.org/10.1016/j.neuron.2006.10.033 PMID: 17178408 
33. Li Z, Jo J, Jia JM, Lo SC, Whitcomb DJ, Jiao S, et al. Caspase-3 activation via mitochondria is required for long-term depression and AMPA receptor internalization. Cell. 2010; 141(5):859-71. https://doi.org/ 10.1016/j.cell.2010.03.053 PMID: 20510932

34. Campbell DS, Holt CE. Apoptotic pathway and MAPKs differentially regulate chemotropic responses of retinal growth cones. Neuron. 2003; 37(6):939-52. PMID: 12670423

35. Westphal D, Sytnyk V, Schachner M, Leshchyns'ka I. Clustering of the neural cell adhesion molecule (NCAM) at the neuronal cell surface induces caspase-8- and -3-dependent changes of the spectrin meshwork required for NCAM-mediated neurite outgrowth. J Biol Chem. 2010; 285(53):42046-57. https://doi.org/10.1074/jbc.M110.177147 PMID: 20961848

36. Rotschafer SE, Allen-Sharpley MR, Cramer KS. Axonal Cleaved Caspase-3 Regulates Axon Targeting and Morphogenesis in the Developing Auditory Brainstem. Front Neural Circuits. 2016; Oct 24; 10:84. https://doi.org/10.3389/fncir.2016.00084 PMID: 27822180

37. Ohsawa S, Hamada S, Kuida K, Yoshida H, Igaki T, Miura M. Maturation of the olfactory sensory neurons by Apaf-1/caspase-9-mediated caspase activity. Proc Natl Acad Sci U S A. 2010; 107(30):1336671. https://doi.org/10.1073/pnas.0910488107 PMID: 20624980

38. Campbell DS, Okamoto $\mathrm{H}$. Local caspase activation interacts with Slit-Robo signaling to restrict axonal arborization. J Cell Biol. 2013; 203(4):657-72. https://doi.org/10.1083/jcb.201303072 PMID: 24385488

39. Kuo CT, Zhu S, Younger S, Jan LY, Jan YN. Identification of E2/E3 ubiquitinating enzymes and caspase activity regulating Drosophila sensory neuron dendrite pruning. Neuron. 2006; 51(3):283-90. https:// doi.org/10.1016/j.neuron.2006.07.014 PMID: 16880123

40. Williams DW, Kondo S, Krzyzanowska A, Hiromi Y, Truman JW. Local caspase activity directs engulfment of dendrites during pruning. Nat Neurosci. 2006; 9(10):1234-6. https://doi.org/10.1038/nn1774 PMID: 16980964

41. Nikolaev A, McLaughlin T, O'Leary DD, Tessier-Lavigne M. APP binds DR6 to trigger axon pruning and neuron death via distinct caspases. Nature. 2009; 457(7232):981-9. https://doi.org/10.1038/ nature07767 PMID: 19225519

42. Simon DJ, Weimer RM, McLaughlin T, Kallop D, Stanger K, Yang J, et al. A caspase cascade regulating developmental axon degeneration. J Neurosci. 2012; 32(49):17540-53. https://doi.org/10.1523/ JNEUROSCI.3012-12.2012 PMID: 23223278

43. Yang J, Weimer RM, Kallop D, Olsen O, Wu Z, et al. Regulation of axon degeneration after injury and in development by the endogenous calpain inhibitor calpastatin. Neuron. 2013; 80(5):1175-89. https:// doi.org/10.1016/j.neuron.2013.08.034 PMID: 24210906

44. Cusack CL, Swahari V, Hampton Henley W, Michael Ramsey J, Deshmukh M. Distinct pathways mediate axon degeneration during apoptosis and axon-specific pruning. Nat Commun. 2013; 4:1876. https://doi.org/10.1038/ncomms2910 PMID: 23695670

45. Unsain N, Higgins JM, Parker KN, Johnstone AD, Barker PA. XIAP regulates caspase activity in degenerating axons. Cell Rep. 2013; 4(4):751-63. https://doi.org/10.1016/j.celrep.2013.07.015 PMID: 23954782

46. Poulain FE, Chien $\mathrm{CB}$. Proteoglycan-mediated axon degeneration corrects pretarget topographic sorting errors. Neuron. 2013; 78(1):49-56. https://doi.org/10.1016/j.neuron.2013.02.005 PMID: 23583107

47. Poulain FE, Gaynes JA, Stacher Hörndli C, Law MY, Chien CB. Analyzing retinal axon guidance in zebrafish. Methods Cell Biol. 2010; 100:3-26. https://doi.org/10.1016/B978-0-12-384892-5.00001-3 PMID: 21111212

48. Kimmel CB, Ballard WW, Kimmel SR, Ullmann B, Schilling TF. Stages of embryonic development of the zebrafish. Dev Dyn. 1995; 203(3):253-310. https://doi.org/10.1002/aja.1002030302 PMID: 8589427

49. Dinkel H, Van Roey K, Michael S, Kumar M, Uyar B, Altenberg B et al. ELM 2016-data update and new functionality of the eukaryotic linear motif resource. Nucleic Acids Res. 2016 Jan 4. 44(D1):D294-300. https://doi.org/10.1093/nar/gkv1291 PMID: 26615199

50. Campanella JJ, Bitincka L, Smalley J. MatGAT: an application that generates similarity/identity matrices using protein or DNA sequences. BMC Bioinformatics. 2003; Jul 10; 4:29. https://doi.org/10.1186/1471 2105-4-29 PMID: 12854978

51. Kumar S, Stecher G, Tamura K. MEGA7: Molecular Evolutionary Genetics Analysis Version 7.0 for Bigger Datasets. Mol Biol Evol. 2016; 33(7):1870-4. https://doi.org/10.1093/molbev/msw054 PMID: 27004904

52. Edgar RC. MUSCLE: multiple sequence alignment with high accuracy and high throughput. Nucleic Acids Res. 2004; 32(5):1792-7. https://doi.org/10.1093/nar/gkh340 PMID: 15034147

53. Waterhouse AM, Procter JB, Martin DMA, Clamp M, Barton GJ. Jalview Version 2-a multiple sequence alignment editor and analysis workbench". Bioinformatics. 20009; 9:1189-1191. 
54. Whelan S, Goldman N. A general empirical model of protein evolution derived from multiple protein families using a maximum-likelihood approach. Molecular Biology and Evolution. 2001; 18: 691-699. https://doi.org/10.1093/oxfordjournals.molbev.a003851 PMID: 11319253

55. Thisse $\mathrm{C}$, Thisse $\mathrm{B}$. High-resolution in situ hybridization to whole-mount zebrafish embryos. Nature protocols. 2008; 3(1): 59-69. https://doi.org/10.1038/nprot.2007.514 PMID: 18193022

56. Masumoto J, Zhou W, Chen FF, Su F, Kuwada JY, Hidaka E, et al. Caspy, a zebrafish caspase, activated by ASC oligomerization is required for pharyngeal arch development. J Biol Chem. 2003; 278 (6):4268-76. https://doi.org/10.1074/jbc.M203944200 PMID: 12464617

57. Eimon PM, Kratz E, Varfolomeev E, Hymowitz SG, Stern H, Zha J, et al. Delineation of the cell-extrinsic apoptosis pathway in the zebrafish. Cell Death Differ. 2006; 13(10):1619-30. https://doi.org/10.1038/sj. cdd.4402015 PMID: 16888647

58. Sakata S, Yan $Y$, Satou $Y$, Momoi A, Ngo-Hazelett $P$, Nozaki M, et al. Conserved function of caspase-8 in apoptosis during bony fish evolution. Gene. 2007; 396(1):134-48. https://doi.org/10.1016/j.gene. 2007.03.010 PMID: 17459614

59. Sakamaki K, Imai K, Tomii K, Miller DJ. Evolutionary analyses of caspase-8 and its paralogs: Deep origins of the apoptotic signaling pathways. Bioessays. 2015; 37(7):767-76. https://doi.org/10.1002/bies. 201500010 PMID: 26010168

60. Wilson KP, Black JA, Thomson JA, Kim EE, Griffith JP, Navia MA, et al. Structure and mechanism of interleukin-1 beta converting enzyme. Nature. 1994; 370(6487):270-5. https://doi.org/10.1038/ 370270a0 PMID: 8035875

61. Martinon F, Tschopp J. Inflammatory caspases and inflammasomes: master switches of inflammation. Cell Death Differ. 2007; 14(1):10-22. https://doi.org/10.1038/sj.cdd.4402038 PMID: 16977329

62. Huang WB, Ren HL, Gopalakrishnan S, Xu DD, Qiao K, Wang KJ. First molecular cloning of a molluscan caspase from variously colored abalone (Haliotis diversicolor) and gene expression analysis with bacterial challenge. Fish Shellfish Immunol. 2010; 28(4):587-95. https://doi.org/10.1016/j.fsi.2009.12. 016 PMID: 20045058

63. Xu L, Yuan S, Li J, Ruan J, Huang S, Yang M, et al. The conservation and uniqueness of the caspase family in the basal chordate, amphioxus. BMC Biol. 2011; Sep 21; 9:60. https://doi.org/10.1186/1741. 7007-9-60 PMID: 21933445

64. Inohara N, Nuñez G. Genes with homology to mammalian apoptosis regulators identified in zebrafish. Cell Death Differ. 2000; 7(5):509-10. https://doi.org/10.1038/sj.cdd.4400679 PMID: 10917738

65. Amores A, Catchen J, Ferrara A, Fontenot Q, Postlethwait JH. Genome evolution and meiotic maps by massively parallel DNA sequencing: spotted gar, an outgroup for the teleost genome duplication. Genetics. 2011; 188(4):799-808. https://doi.org/10.1534/genetics.111.127324 PMID: 21828280

66. Glasauer SM, Neuhauss SC. Whole-genome duplication in teleost fishes and its evolutionary consequences. Mol Genet Genomics. 2014; 289(6):1045-60. https://doi.org/10.1007/s00438-014-0889-2 PMID: 25092473

67. Takle H, McLeod A, Andersen O. Cloning and characterization of the executioner caspases 3, 6, 7 and Hsp70 in hyperthermic Atlantic salmon (Salmo salar) embryos. Comp Biochem Physiol B Biochem Mol Biol. 2006; 144(2):188-98. https://doi.org/10.1016/j.cbpb.2006.02.006 PMID: 16574452 